\title{
Activation of a7nAChR Preserves Intestinal Barrier Integrity and Ameliorates Cholestasis Liver Fibrosis in Mice by Enhancing the HO-1 / STAT3 Signaling to Inhibit NF-kB Activation
}

\section{Wei Lei}

First Affiliated Hospital of Dalian Medical University

cheng chang Zhao

First Affiliated Hospital of Dalian Medical University

sen jia Sun

First Affiliated Hospital of Dalian Medical University

ling yan Jin

First Affiliated Hospital of Dalian Medical University

jun zhi Duan ( $\square$ cathydoctor@sina.com )

Dalian Medical University https://orcid.org/0000-0001-7976-4959

\section{Research}

Keywords: an7AChR, HO-1, cholinergic anti-inflammatory pathway, STAT3, PI3K, co-culture, intestinal barrier

Posted Date: July 13th, 2021

DOl: https://doi.org/10.21203/rs.3.rs-696245/v1

License: (c) (i) This work is licensed under a Creative Commons Attribution 4.0 International License. Read Full License 


\section{Abstract}

Background. Activation of alpha-7 nicotinic acetylcholine receptor (a7nAChR) can inhibit the systemic inflammatory response and preserve intestinal barrier integrity. This study aimed at elucidating the molecular mechanisms by which a7nAChR activation could inhibit intestinal barrier injury and cholestatic liver fibrosis in mice induced by bile duct ligation (BDL).

Methods: The intestine-specific HO-1 knockout VillinCreHmox $1^{-/-}$and control Hmox $1^{\text {floxp/floxp }}$ C57BL/6 mice were subjected to BDL. The therapeutic effects of GST-21, a specific ligand for a7nAChR, on systemic and intestinal inflammation, intestinal barrier integrity, liver fibrosis and injury, HO-1 expression, STAT3, AKT and NF-kBp65 activation were examined in these mice and intestinal epithelial cells cocultured with macrophages.

Results: Compared with BDL mice, a7nAChR activation by GST-21 decreased intestinal and liver injury and fibrosis in BDL mice, accompanied by reducing serum cytokine responses. In addition, activation of a7nAChR preserved the tight junction protein expression and intestinal epithelial cell barrier integrity in $\mathrm{BDL}$ mice and epithelial cells co-cultured with macrophages. The therapeutic effects of a7nAChR activation were mediated by enhancing HO-1 expression, STAT3 phosphorylation, and reducing the NFkBp65 activation in intestinal tissues and epithelial cells co-cultured with macrophages. Finally, activation of a7nAChR induced HO-1 expression and STAT3 phosphorylation in an interdependent manner, independent of the PI3K/AKT signaling.

Conclusion: Activation of a7nAChR enhanced HO-1 expression and STAT3 signaling to inhibit NF-KB activation, preserving the intestinal barrier integrity, and reducing inflammation and liver fibrosis in cholestasis mice. Therefore, targeting a7nAChR may be a promising interventional strategy for primary biliary cholangitis.

\section{Introduction}

Primary biliary cholangitis (PBC) is a chronic autoimmune liver disease characterized by non-suppurative small duct and portal inflammation and interface hepatitis[1]. PBC affects the life quality of patients and its progression eventually leads to biliary cirrhosis and liver failure. Unfortunately, there are no specific and effective therapies for PBC. Pathophysiologically, PBC has been attributed to intestinal barrier injury[2], which is evidenced by commonly clonal T cells homing in the intestine and liver of PBC patients, suggesting that unknown antigens in the intestine stimulate immune responses, leading to the development of PBC [3]. The loss of intestinal barrier integrity also allows commensal organisms and foodborne antigens to enter the liver, exacerbating hepatic inflammation and PBC[4]. Hence, the functional deficiency in the gut-liver axis is a major contributor to PBC development. However, it is unclear whether preservation of intestinal barrier integrity can be a valuable strategy for the intervention of PBC.

Nicotinic acetylcholine receptors (nAChRs) can be activated by its natural ligand of the neurotransmitter acetylcholine (Ach) [5]. Nicotinic acetylcholine receptor a7 (a7nAChR) is crucial for long-term memory and 
immune regulation[6]. The $a 7 n A C h R$ is mainly expressed in the brain and immune cells, such as macrophages and activation of a7nAChR by Ach in tissue macrophages and other immune cells can inhibit their production of pro-inflammatory cytokines, such as IL-1 $\beta$, IL- 6 and TNFa, known as the "cholinergic anti-inflammatory pathway" (CAP) [7, 8]. Actually, activation of the CAP can alleviate acute and chronic inflammatory diseases, such as endotoxemia and inflammatory bowel disease in rodents[9, 10]. In addition, activation of a7nAChR by neuronal and non-neuronal Ach can ameliorate intestinal, cardiovascular and lung inflammation, neurodegeneration, sepsis and arthritis[11-14]. In contrast, chronic nicotine exposure can stimulate biliary cholangiocyte proliferation and induce pro-fibrotic protein expression by enhancing the Calcium/ERK signaling in healthy adult rats[15]. However, little is known on whether and how activation of the a7nAChR can affect the pathogenic process of bile duct ligation (BDL)-induced inflammation and fibrosis.

The PI3K/AKT and JAK2/STAT3 pathways are important for the anti-inflammatory effects of a7nAChR activation[16, 17]. STAT3 knockout mice can enhance the inflammatory activity of macrophages and neutrophils[18]. Activation of a7nAChR by Ach can enhance the STAT3 signaling that positively feedback up-regulates a7nAChR expression to amplify the anti-inflammatory effect of Ach/ a7nAChR. Furthermore, the activated STAT3 can also enhance nuclear factor erythrocyte-associated factor 2 (NRF2) activation and promote the expression of Heme oxygenase 1(HO-1) and other antioxidant enzymes[19, 20]. HO-1 and its metabolic byproducts, such as carbon monoxide (CO), biliverdin, and ferrous iron, have potent antioxidant and anti-inflammatory activities[20]. Activation of the CAP also increases HO-1 expression and enhances the a7nAChR activation-related inhibition of nerve injury, myocardial ischemia-reperfusion injury, and intestinal barrier injury[12, 21,22]. However, the exact mechanisms by which activation of a7nAChR inhibits the production of pro-inflammatory factors in gastrointestinal immune cells has not been clarified although it can alleviate intestinal inflammation and maintain the integrity of intestinal epithelium[23, 24]. Up-regulated HO-1 expression can ameliorate endotoxemic inflammatory responses in macrophages[25] and preserve the intestinal barrier integrity in cholestasis rats[26]. Accordingly, we hypothesize that activation of $\mathrm{a} 7 \mathrm{nAChR}$ can up-regulate anti-inflammatory HO-1 expression in intestinal epithelial cells to preserve the intestinal barrier integrity in early cholestatic liver injury by modulating the PI3K/AKT and JAK/STAT3 signaling.

In the present study, we tested the therapeutic effect of GTS-21, a specific a7nAChR agonist, on cholestatic liver injury, intestinal barrier integrity, inflammatory cytokine production in a mouse model of BDL-induced cholestatic liver injury and investigated whether activation of a7nAChR modulated the intestinal epithelial barrier integrity by enhancing HO-1 expression and the PI3K/AKT/STAT3 signaling.

\section{Materials And Methods}

\section{Cell culture and treatments}

Human myeloid leukemia U-937, murine macrophage RAW264.7 and human colonic epithelial HT29 cells were cultured in RPMI-1640 medium supplemented with 10\% fetal bovine serum (FBS), $100 \mathrm{U} / \mathrm{mL}$ of 
penicillin, and $100 \mu \mathrm{g} / \mathrm{mL}$ of streptomycin (Gibco) at $37^{\circ} \mathrm{C}, 95 \%$ humidity and $5 \% \mathrm{CO}_{2}$.

U937 monocytes were treated with $100 \mathrm{ng} / \mathrm{ml}$ of phorbol 12-myristate 13-acetate (PMA; Sigma-Aldrich) for 48 hours to induce their differentiation into macrophages for the following experiments[27]. U937 macrophages and RAW264.7 cells were pretreated with, or without, $10 \mu \mathrm{M} \mathrm{GTS-21} \mathrm{(MCE)} \mathrm{for} 6$ hours, and stimulated with $1 \mu \mathrm{g} / \mathrm{ml}$ of lipopolysaccharide (Escherichia coli 055: B5; Sigma-Aldrich) for 24 hours [28].

\section{Transduction of human epithelial Caco2 (HO-1 shRNA) cells with lentivirus}

Human colonic epithelial Caco2 cells were transduced with control lentivirus or lentivirus for the expression of HO-1 specific shRNA (Hanbio Biotechnology, Shanghai, China) using Lipofiter TM (Hanbio Biotechnology, Shanghai, China) and the cells were selected with puromycin $(4 \mu \mathrm{g} / \mathrm{mL})$ for one week to establish Caco2-HO-1/sh and control Caco2-Con cells. The sequence of shRNA targeting HO-1 was FCCGGACAGTTGCTGTAGGGCTTTATCTCGAGATAAAGCCCTACAGCAACTGTTTTTTG; RAATTCAAAAAACAGTTGCTGTAGGGCTTTATCTCGAGATAAAGCCCTACAGCAACTGT. The efficacy of HO-1 silencing was evaluated by RT-qPCR and Western blot assays (Supplemental Fig. 1).

\section{Co-culture of epithelial cells with U937 macrophages}

Caco2-H0-1-sh or control Caco2-Con cells as well as HT29 were co-cultured with U937 macrophages in 6well transwell plates (0.4- $\mu \mathrm{m}$ pore size; Corning). U937 macrophages $\left(3 \times 10^{5}\right.$ cells/well) were loaded in the upper chamber and Caco2-H0-1-sh, control Caco2-Con or HT29 cells $\left(1 \times 10^{6}\right.$ cells/well) were added in the bottom chamber[29]. The macrophages were pre-treated with $10 \mu \mathrm{M}$ GTS-21 and stimulated with $1 \mu \mathrm{g} / \mathrm{ml}$ LPS for 24 hours, followed by stimulating epithelial cells with $10 \mu \mathrm{g} / \mathrm{mL}$ LPS for 24 hours[26]. In some experiments, the epithelial cells were pretreated with $20 \mu \mathrm{M}$ Stattic (a STAT3 inhibitor, MCE, USA) or 50 HM LY294002 (a PI3K inhibitor, MCE) for 12 hours before co-culture[30, 31]. A schematic diagram of the co-culture experiment is shown in Supplemental Fig. 2.

\section{Animals}

The experimental protocols were approved by the Animal Care and Use Committee of Dalian Medical University (Liaoning Province, China; approval ID AEE19011). The VillinCreHmox $1^{-/-}$(the intestine-

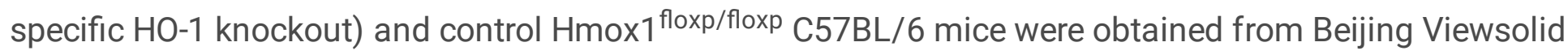
Biotechnology (Beijing, China). The mice were housed in a specific pathogen-free room with a consistent temperature $\left(20-22^{\circ} \mathrm{C}\right)$ and a cycle of $12 / 12$-h light/dark and allowed to free access to normal rodent chow and water.

\section{Animal model, grouping and treatment}

Male mice at 10 weeks of age were injected intraperitoneally with $40 \mathrm{mg} / \mathrm{kg}$ pentobarbital (Sigma, USA) and subjected to sham or BDL procedure[32]. Briefly, their cystic and common bile ducts of individual BDL mice were exposed by an incision and ligated using $8-0$ nylon suture. The sham group of mice received a sham surgery without ligation. After their abdomen was closed, the mice were kept on a 
heatpad until their awake. The BDL mice were randomized and injected intraperitoneally with vehicle (BDL group) or GTS-21 (8 mg/kg) and saline, Stattic (25 mg/kg) or LY294002 $(0.5 \mathrm{mg} / \mathrm{kg}$, MCE, USA) every other day for six treatments. The VillinCreHmox $1^{\text {floxp/floxp }}$ mice received BDL and GTS-21 injection. As a result, there were seven groups: Sham, BDL, BDL + GTS-21, BDL + GTS-21 + saline, BDL + GTS-21 + VillinCreHmox1-/, BDL + GTS-21 + Stattic and BDL + GTS-21 + LY294002 ( $n=6-8$ per group). The mice were given different drugs 6 hours apart on the same day[14,33-35]. The mice in the Sham and BDL groups received the same dose of vehicle saline. At 14 days post-BDL, their blood samples were collected for preparing serum samples and their intestinal and liver tissues were dissected for experimental examinations.

\section{Enzyme-linked immunosorbent assay (ELISA)}

The levels of serum IL-1 $\beta$, IL-6, IL-10, TNFa, alanine aminotransferase (ALT) and aspartate transaminase (AST) in individual mice were quantified in triplicate by ELISA using specific kits (Elabscience, China) according to the manufacturer's instructions.

\section{Histological examination}

Liver and intestinal tissues were fixed in $4 \%$ paraformaldehyde and paraffin-embedded. The liver and intestinal tissue sections $(4 \mu \mathrm{m})$ were routine-stained with hematoxylin and eosin (H\&E). The degrees of liver fibrosis were scored and the levels of intestinal mucosal injuries were scored using the Chiu's scoring system in a blinded manner[26, 36]. The liver sections were stained with Picrosirius-red using the Siriusred staining kit (Solarbio, Beijing, China). The amount of collagen deposition was measured using a computerized image-analysis system and expressed as the percentages of the positively stained area in total area.

\section{Immunohistochemistry and Immunofluorescence}

The levels of targeted protein expression in intestinal and liver tissue samples were examined by immunohistochemistry and immunofluorescence. Briefly, intestinal and liver tissue sections $(4 \mu \mathrm{m})$ were dewaxed, rehydrated and treated with $3 \% \mathrm{H}_{2} \mathrm{O}_{2}$, followed by blocking with $3 \%$ bovine serum albumin (BSA, Sigma-Aldrich). The sections were probed overnight with primary antibodies at $4^{\circ} \mathrm{C}$, and reacted with horseradish peroxidase (HRP)-conjugated secondary antibodies, followed by visualizing with a DAB substrate kit (Abcam, ab64238). For Immunofluorescence, the tissue sections and cells were permeabilized in $0.3 \%$ Triton X 100 and blocked with 5\% BSA. After probing with primary antibodies overnight at $4^{\circ} \mathrm{C}$, the bound antibodies were detected with fluorescein isothiocyanate (FITC)-conjugated goat anti-rabbit lgG (Santa Cruz Biotech, CA). The negative controls were probed with the vehicle solution. The fluorescent signals were examined under a confocal microscope (Olympus, Tokyo, Japan). The primary antibodies included anti- phosphor-NF-KB (ab194726, 1:100 dilution), anti-HO-1 (ab13248, 1:100 dilution), anti-phospho-STAT3 (ab76315, 1:100 dilution), anti-a7nAchR (ab216485, 1:200 dilution), and anti-ZO1 (Abcam, ab96587, 1:500 dilution).

\section{Measurement of cell and intestinal barrier permeability}


Caco- 2 cells $\left(3 \times 10^{5}\right.$ cells/well) were cultured in the upper chamber of the transwell plates for 10 days to form a monolayer. RAW264.7 cells $\left(2 \times 10^{6}\right.$ cells/well) were cultured in the bottom chamber. Cells are treated as described above. The cell culture was replaced with serum free medium and incubated for another $30 \mathrm{~min}$, and the transepithelial electrical resistance (TEER, $\Omega / \mathrm{cm}^{2}$ ) was evaluated using a resistance measuring instrument (Millipore, USA). Subsequently, the epithelial cells in the upper chamber were treated with $100 \mu \mathrm{g}$ FITC-dextran - 4 (FD-4, Sigma) and incubated in $37^{\circ} \mathrm{C}$ for $30 \mathrm{~min}$. After that, 100 $\mu \mathrm{l}$ of medium from the bottom chamber were measured for the fluorescence contents using the BioTek Cytation 3 with an excitation of $480 \mathrm{~nm}$ and emission of $520 \mathrm{~nm}$ respectively. In addition, individual mice were orally administrated by gavage with $12 \mathrm{mg} \mathrm{FD}-4$ in $150 \mu \mathrm{l}$ of sterile water at 13 days post BDL. The next day, their venous blood samples $(100 \mu \mathrm{L}$ each) were collected and the levels of FITC fluorescence in individual samples were measured using the BioTek Cytation3.

\section{Real-time quantitative PCR (RT-qPCR)}

Total RNA was extracted from the cell and tissue samples using TRIzol (Transgene Biotech) and reversely transcribed into cDNA using the Prime Script ${ }^{\text {TM }}$ RT Reagent Kit (Takara). The relative levels of interesting gene mRNA transcripts to the control $\beta$-actin were quantified by RT-qPCR in the ABI7500 RT-PCR detection system (ABI System) using SYBR® Green RT-PCR Master Mixes (ABI System) and specific primers (Supplemented Table 1). The PCR reactions were performed in duplicate at $95^{\circ} \mathrm{C}$ for $10 \mathrm{~min}$ and subjected to 40 cycles of $95^{\circ} \mathrm{C}$ for $15 \mathrm{~s}$ and $60^{\circ} \mathrm{C}$ for $1 \mathrm{~min}$. The data were analyzed by $2^{-\Delta \Delta \mathrm{Ct}}$.

\section{Western blot analysis}

Individual tissue samples were homogenized and cultured cell samples were lysed in lysis buffer. After quantification of protein concentrations using the BCA kit (Beyotime, China), the lysate samples (30 $\mu \mathrm{g} /$ lane) were resolved by sodium dodecyl sulfate polyacrylamide gel electrophoresis (SDS-PAGE) on $12 \%$ gels and transferred onto polyvinylidene difluoride (PVDF) membranes. The membranes were blocked and probed with primary rabbit antibodies (Supplemented Table 2) at $4^{\circ} \mathrm{C}$ overnight and reacted with HRP-conjugated secondary antibodies (Abclonal, China, 1:2000 dilution), followed by visualizing using a chemiluminescent kit (Advasta). The relative levels of targeted proteins to the control $\beta$-actin were quantified by densitometry analysis using ImageJ software.

\section{Statistical analysis}

Data are presented as the mean \pm SEM of each group from three or more independent experiments. The difference among groups was analyzed by ANOVA and post hoc Tukey test or Student's T-test using GraphPad Prism version 7 (GraphPad Software, La Jolla, CA). A P-value of $<0.05$ was considered statistically significant.

\section{Results}

3.1 Activation of $\mathrm{a} 7 \mathrm{nAChR}$ attenuates inflammation and liver functional impairment in BDL mice and modulates the LPS-induced cytokine transcription in macrophages in vitro. 
To explore the effect of $a 7 n A C h R$ activation on inflammation and liver injury, we established in a mouse model of cholestatic liver injury by BDL and found that BDL significantly decreased body weights at 14 days post-BDL regardless of treatment and HO-1 KO ( $p<0.001$, for all, Fig. 1a). In comparison with the sham control, BDL did not significantly alter the relative levels of $a 7 n A C h R$ expression in intestinal tissues, but treatment with GST-21 significantly up-regulated a7nAChR protein expression in intestinal tissues of different groups of BDL mice, regardless of intestinal HO-1 KO, STAT3 or AKT inhibition $(p<$ 0.05 , Fig. S3a-b). Furthermore, BDL significantly increased the levels of serum IL-1 $\beta$, IL- 6 and TNFa in mice $(p<0.01, p<0.001)$, which were significantly mitigated in GTS-21 treated mice at 14 days post-BDL $(p<0.05, p<0.01)$, but not in the mice received with Stattic treatment and the Villin-CreHmox1-/- mice (Fig. 1b-d). A similar pattern of serum ALT and AST levels was detected in the different groups of mice at 14 days post-BDL, except for the insignificant difference in the levels of AST between the GST-21 treated Hmox $1^{\text {floxp/floxp }}$ and Villin-CreHmox1-/- mice (Fig. 1e-f). To further understand the effect of a7nAChR activation, we tested how treatment GST-21 could modulate the LPS-stimulated cytokine production in macrophages in vitro. We found that treatment with GST-21 alone did not significantly change the relative levels of IL-1 $\beta$, IL-6, TNFa, IL-22 and IL-10 mRNA transcripts in both U939 and RAW264.7 macrophages, but GST-21 treatment significantly mitigated the LPS-increased IL-1 $1 \beta$, IL- 6 and TNFa mRNA transcripts and further elevated IL-22 and IL-10 mRNA transcripts in these macrophages in vitro $(p<0.001$ for all, Fig. $1 \mathrm{~g}-\mathrm{k}$ and $\mathrm{I}-\mathrm{p}$ ). These data indicated that activation of $\mathrm{a} 7 \mathrm{nAChR}$ significantly alleviated the BDLinduced inflammatory cytokine responses and liver injury in mice, dependent on intestinal HO-1 expression and STAT3 activity, but not PI3K/AKT activity and modulated the LPS-induced cytokine gene transcription in macrophages in vitro.

\subsection{Activation of a7nAChR ameliorates intestinal mucosal damages and liver fibrosis in BDL mice, dependent on intestinal HO-1 and STAT3 activity.}

To further explore the protective effect of a7nAChR activation on intestinal mucosal damages and liver fibrosis, we histologically evaluated intestinal mucosal damages and liver fibrosis in different groups of mice. Following H\&E staining, we observed villous necrosis, inflammatory infiltrates and hemorrhage in the intestinal mucosa of the BDL group were much severer than those in the sham and GST-21 treated mice (Fig. 2a). Similarly, there are many necrotic hepatocytes and inflammatory infiltrates as well as the enlargement of fibrous tissue surrounding the portal area, a fibrous septum formation in the liver of BDL mice. Further Sirius Red staining revealed varying levels of collagen deposition in the liver, particularly in the BDL mice without GST-21 treatment. Quantitative analysis indicated Chiu's histological scores of intestinal mucosal damages in individual mice (Table S3) and that Chiu's histological scores in the BDL group were significantly higher than that in the sham group, but were significantly reduced in the GST-21 treated mice, except for those received Stattic or HO-1 ${ }^{-/-}$mice (Fig. 2b). A similar pattern of liver fibrosis grades (detailed pathological grades in Table S4) and collagen deposition contents was detected in the livers of different groups of mice, except for the insignificant difference in the liver fibrosis grades between wild-type and $\mathrm{HO}^{-1^{-/}}$mice as well as the insignificant difference in the collagen deposition contents between the GST-21 treated mice and LY294002-treated mice (Fig. 2c-f). These results indicated 
that activation of $a 7 n A C h R$ ameliorated intestinal mucosal damages and liver fibrosis in BDL mice, variably dependent on intestinal HO-1 expression, STAT3 and/or PI3K/AKT activities.

\subsection{Activation of $a 7 n A C h R$ preserves the expression of tight junction proteins and intestinal epithelial barrier integrity in vivo and in vitro}

Given that tight junction proteins are crucial for intestinal barrier integrity, we investigated the levels of ZO-1, Occludin and Claudin-1 expression in intestinal tissues from different groups of mice by Western blot and RT-qPCR assays. We found that compared to the sham group, BDL significantly reduced the relative levels of ZO-1, Occludin and Claudin-1 protein expression in intestinal tissues of mice, which was partially rescued by GST-21 treatment (Fig. 3a-d). However, the preservation of tight junction protein expression by GST-21 was attenuated in intestinal $\mathrm{HO}-1^{-/-}$mice and by treatment with Stattic in mice. A similar pattern of ZO-1, Occludin and Claudin-1 mRNA transcripts was detected in the intestinal tissues of different groups of mice, except for significantly reduced levels of Z0-1 and Claudin-1 mRNA transcripts in the LY294002-treated mice (Fig. 3e-g). Functionally, we found that treatment with GST-21 significantly mitigated the BDL-increased serum levels of FITC-dextran, and the therapeutic effect of GST-21 on preserving intestinal barrier integrity was partially reduced in the Stattie-treated mice or intestinal HO-1-/mice (Fig. 3h). These demonstrated that activation of a7nAChR mitigated the BDL-increased intestinal barrier permeability by preserving tight junction protein expression in the intestinal tissues of mice.

Next, we validated the results in a cellular model. Given that the a7nAChR is mainly expressed in immune cells, such as macrophages in the periphery, we measured how GST-21 treatment modulated tight junction protein expression and monolayer epithelial permeability in a co-culture system. Following culture alone or co-culture with macrophages, we found that treatment with GST-21 did not significantly change the LPS-decreased ZO-1, Occludin and Claudin-1 expression in cultured intestinal epithelial Caco2 or HT29 cells alone, but GST-21 treatment completely blocked the LPS-decreased ZO-1, Occludin and Claudin-1 expression when these epithelial cells co-cultured with macrophages (Fig. 3i-l and m-p). Moreover, a similar pattern of TEER was detected in the different groups of cells, indicating that GST-21 treatment restored the LPS-decreased TEER of monolayer epithelial cells when co-culture with macrophages (Fig. 3q). Additionally, GST-21 treatment also significantly reduced the LPS-increased FITCdextran contents in the supernatants of co-cultured cells (Fig. 3r-s), suggesting that activation of a7nAChR in macrophages by GST21 preserved the intestinal epithelial monolayer integrity in the coculture system. Immunofluorescence revealed that compared with the control Caco2 cells alone, LPS treatment decreased ZO-1 expression, which was not affected by GST-21 (Fig. 3t). In contrast, GST-21 treatment significantly mitigated the LPS-decreased ZO-1 expression and cytoskeletal structural damages in the Caco 2 cells when co-cultured with macrophages in vitro. Together, these data demonstrated that activation of $\mathrm{a} 7 \mathrm{nAChR}$ in immune cells, such as macrophages, significantly preserved tight junction protein expression and intestinal epithelium integrity in vivo, dependent on HO-1 expression and STAT3 activity and in the vitro co-culture system. 


\subsection{Activation of a7nAChR in macrophages enhances the LPS-stimulated H0-1 and IL-10 expression in intestinal epithelial cells and tissues.}

Given that HO-1 and IL-10 are important for intestinal barrier function we tested whether treatment with GST-21 to activate a7nAChR in macrophages could modulate HO-1 and IL-10 expression in the monolayer of intestinal epithelial cells [27]. We found that treatment with LPS, but not GST-21, obviously increased the levels of HO-1 expression in Caco2 and HT29 cells while treatment with GST-21 failed to alter HO-1 expression in the LPS-treated cells (Fig. 4a-c and d-e). In contrast, treatment with GST-21 further enhanced the LPS-increased HO-1 and IL-10 expression in both Caco2 and HT29 cells when co-cultured with macrophages (Fig. 4a-f). Furthermore, the enhanced HO-1 expression by GST-21 was significantly reduced by HO-1 silencing or treatment with Stattic, but not with LY294002 in both Caco2 when cocultured with macrophages (Fig. 4g-i). Similarly, BDL significantly increased the levels of HO-1 expression in intestinal tissues while GST-21 treatment further enhanced the BDL-increased HO-1 expression in intestinal tissues, which was failed in $\mathrm{HO}-1^{-/-}$mice, and significantly mitigated in the Stattic-treated mice, but not in the LY294002-treated mice (Fig. 4j-I). Moreover, GST-21 treatment also further increased the LPS-enhanced IL-10 expression in Caco2 cells when co-cultured with macrophages, which was no affected by HO-1 silencing and Ly294002 treatment (Fig. 4m). In contrast, treatment with Stattic to inhibit STAT3 activity significantly attenuated the GST-21-enhanced HO-1 expression in Caco 2 cells that were cocultured with macrophages. Additionally, GST-21 treatment enhanced the BDL-up-regulated IL-10 expression in intestinal tissues, which was not affected by HO-1 knockout, but significantly mitigated by treatment with Stattic or ly294002 in intestinal tissues of mice (Fig. 4n) These results indicated that activation of a7nAChR in macrophages enhanced the LPS or BDL-up-regulated HO-1 and IL-10 expression in intestinal epithelial cells, which may be partially dependent on the STAT3 signaling.

\subsection{Activation of a7nAChR enhances the HO-1/STAT3 and PI3K/AKT signaling to attenuate NF-KB activation in vitro and in vivo.}

Finally, we explored how activation of a7nAChR enhanced HO-1 expression and modulated the STAT3, $\mathrm{PI3K} / \mathrm{AKT}$ and NF-kB signaling in intestinal epithelial cells and intestinal tissues of BDL mice. After knockdown of HO-1 expression in Caco2 cells, we found that compared with the control cells, LPS upregulated HO-1 expression and treatment with GST-21 further significantly elevated the relative levels of HO-1 expression in Caco2 cells when co-cultured with macrophages, which were dramatically reduced by HO-1 silencing and partially mitigated by Stattic treatment (Fig. 5a-e). Furthermore, LPS treatment also enhanced STAT3, AKT and NF-kBp65 phosphorylation and treatment with GST-21 significantly increased STAT3 and AKT phosphorylation, but decreased NF-kBp65 phosphorylation in Caco2 cells. The therapeutic effect of GST-21 on STAT3 and AKT phosphorylation was abrogated by HO-1 silencing, Stattic or LY294002 treatment in Caco2 cells. Moreover, HO-1 silencing, Stattic and LY294002 treatment also abrogated the GST-21-decreased NF-kBp65 phosphorylation in LPS-treated Caco2 cells. These data suggest that activation a7nAChR would enhance HO-1 expression by enhancing the STAT3 and $\mathrm{PI} 3 \mathrm{~K} / \mathrm{AKT}$ signaling to attenuate the NF-kB activation in intestinal epithelial cells when co-cultured with macrophages, preserving the intestinal barrier integrity. Similarly, GST-21 treatment further enhanced the 
BDL-up-regulated HO-1 expression, STAT3 and AKT phosphorylation but dramatically mitigated the BDLinduced NF-kBp65 phosphorylation in intestinal tissues of the different groups of mice (Fig. 5f-j). In addition, HO-1 knockout, Stattic or LY294002 treatment significantly mitigated or abrogated the GST-21enhanced HO-1 expression, STAT3 and AKT activation, but partially rescued NF-kBp65 activation in intestinal tissues of different groups of mice, except that LY294002 treatment failed to significantly modulate the GST-21-enhanced HO-1 expression. These data further indicated that activation of a7nAChR enhanced HO-1 expression by enhancing the STAT3 and PI3K/AKT signaling to attenuate the NF-kB activation in intestinal tissues, contributing to inhibition of cholestatic liver fibrosis in mice.

Immunohistochemistry revealed that compared with the control, the anti-p-STAT3 signals increased in intestinal tissues of the BDL group and were further stronger in the GST-21 or LY294002 group (Fig. 6a). In contrast, the anti-pSTAT3 signals were much weaker in the $\mathrm{HO}-1^{-/-}$or Stattic group than in the GST-21 group. A similar pattern of anti-HO-1 staining signals was observed in intestinal tissues of different groups of mice, consistent with the results from the Western blot assay (Fig. 6b). In contrast, the strongest anti-pNF-kBp65 signals were observed in intestinal tissues of the BDL group, which were dramatically reduced in the GST-21 group (Fig. 6c). The anti-pNF-kBp65 signals were completely or partially rescued in the $\mathrm{HO}^{-1^{-/}}{ }^{-}$, Stattic or LY294002 group of mice. These three lines of evidence demonstrated that activation of a7nAChR up-regulated HO-1 expression by enhancing the STAT3 signaling to attenuate the NF-kB activation in intestinal tissues, preserving the intestinal barrier integrity and inhibiting cholestatic liver fibrosis in mice.

\section{Discussion}

High concentrations of bile acids, especially more toxic hydrophobic bile acids, will damage cholangiocytes and hepatocytes, leading to cholestasis, which progressively causes liver fibrosis and even cirrhosis[37]. The intestinal barrier damages have been associated with the development of cholestatic liver diseases. However, it is still unclear whether intestinal barrier dysfunction is a cause or consequence of cholestatic liver disease, such as PBC. Nonetheless, impairment of intestinal barrier integrity is often observed in patients with many diseases[38], and intestinal barrier integrity has been thought to be a therapeutic target.

In this study, we employed a mouse model of BDL-induced cholestatic liver fibrosis and an intestinal epithelium-macrophage co-culture system to investigate the therapeutic effects of a7nAChR activation on the intestinal barrier integrity and to explore its possible mechanism. The available data highlighted that GTS-21 treatment to activate a7nAChR attenuated systemic inflammation, intestinal and liver injury and fibrosis by preserving the intestinal barrier integrity in BDL mice. Evidently, GST-21 treatment increased serum IL-10, but decreased serum TNF-a, IL- 6 and IL-1 $\beta$, ameliorating the imbalance of pro-inflammatory and anti-inflammatory cytokine responses in BDL mice. Furthermore, activation of a7nAChR preserved the expression of ZO-1, Occludin and Claudin-1 tight junction proteins in intestinal tissues to reduce the intestinal barrier permeability in BDL mice. Mechanistically, we found that activation of a7nAChR enhanced HO-1 expression and STAT3 activation, but attenuated the NF-KB signaling in intestinal tissues 
of BDL mice. Similar data were obtained from in vitro epithelial cells co-cultured with macrophages. More importantly, the therapeutic effects of a7nAChR activation were abrogated by HO-1 deficiency and significantly mitigated by inhibition of STAT3 activity in intestinal epithelial cells in vivo and in vitro. These novel findings may uncover the therapeutic mechanisms underlying the action of a7nAChR activation in preserving the intestinal barrier integrity and inhibiting cholestatic liver fibrosis. Therefore, a7nAChR may be a therapeutic target for the intervention of cholestatic liver fibrosis, such as PBC.

A previous study has shown that inflammation, but not the direct toxicity of bile acids is a dominant factor of cholestatic liver fibrosis[39]. In the present study, we found that BDL significantly increased serum levels of TNFa, IL-1 $\beta$, and IL- 6 in mice, which may directly damage cholangiocytes and reduce the expression of bile transporters in cholangiocytes, increasing the accumulation of bile acids in the liver and deteriorating liver injury and fibrosis[40]. Actually, a reduction in pro-inflammatory cytokine production and inhibiting the inflammatory pathway can drastically mitigate the liver injury, retarding the process of cirrhosis in BDL rodents [41]. We found that activation of a7nAChR significantly decreased serum levels of TNFa, IL-1 $\beta$ and IL-6 in BDL mice, which were associated with liver injury in BDL mice. Our data support the notion that inflammation is crucial for the development and progression of cholestatic liver injury. Conceivably, control of inflammation may be a valuable strategy for the intervention of cholestatic liver diseases, such as PBC.

The dysfunctional gut-liver axis is closely related to the pathogenesis of chronic liver disease because the liver is the most vulnerable organ for gut microbial infection [42]. Bacteria and their metabolites can through the disrupted intestinal barrier enter the bile duct and liver to enhance inflammation that deteriorates cholestatic liver injury[43]. It is well known that ZO-1, Occludin, and claudin-1 and others are important for intestinal barrier integrity[44]. We found that BDL dramatically decreased these tight junction proteins expression in intestinal tissues, accompanied by increased intestinal barrier permeability in mice, consistent with the findings from other models[45]. Similarly, LPS treatment also damaged the monolayer of the intestinal epithelial cell barrier and increased its permeability in a coculture system, similar to a previous observation[46]. In contrast, activation of a7nAchR preserved the tight junction protein expression and mitigated the BDL or LPS-increased intestinal barrier permeability in vivo and in vitro. These findings support the concepts that disrupted intestinal barrier integrity and bacterial infection participate in the pathogenesis of cholestatic liver injury. Preserving and restoring intestinal barrier integrity may inhibit the progression of cholestatic liver injury. We are interested in further investigating how BDL or cholestasis disrupts the intestinal barrier integrity.

Activation of the CAP, particularly for the a7nAChR, can inhibit the inflammatory pathogenesis of several diseases, including acute lung inflammation and acute pancreatitis[47, 48]. In this study, we found that activation of $\alpha 7 n A C h R$ not only decreased pro-inflammatory IL-1 $\beta$, IL 6 and TNFa production but also enhanced IL-10 and IL-22 production in macrophages under a LPS stimulation. IL-10 is a potent antiinflammatory cytokine and can inhibit different types of immune and inflammatory responses. IL-22 can be secreted by different types of cells, including macrophages and stimulate other types of cells to produce antimicrobial peptides and proteins to defense bacterial infection, particularly in the intestine[49]. 
Functionally, IL-22 can through its receptors of IL-10R2/IL-22R1 promote epithelial cell proliferation, survival and repair to enhance the intestinal barrier integrity although it can synergistically work with IL17A or TNFa to enhance pro-inflammatory responses in some pathological conditions[50, 51]. The decreased pro-inflammatory cytokines and increased IL-10 and IL-22 by GST-21 treatment clearly demonstrate that $\mathrm{a} 7 \mathrm{nAChR}$ activation can alleviate the imbalance of pro-inflammatory and antiinflammatory responses, particularly in an intestinal bacterial infection, to preserve the intestinal barrier integrity. Therefore, the intestinal-intrinsic $a 7 n A C h R$ signaling may serve as an endogenous protective modality for intestinal barrier integrity to inhibit cholestatic liver injury.

$\mathrm{HO}-1$, an anti-inflammatory and anti-oxidant protein, can inhibit oxidative stress-related inflammation to protect from different types of damage during the pathogenic process of intestinal diseases, liver injury and pulmonary inflammation[52,53]. Actually, elevated H0-1 expression can increase the expression of tight junction proteins to preserve the intestinal barrier integrity in mice with cholestatic liver injury and $\mathrm{CCl} 4$ injected mice[26, 52]. We found that a7nAChR activation up-regulated HO-1 expression in intestinal tissues in BDL mice and epithelial cells co-cultured with macrophages, consistent with previous observations[54]. Moreover, a7nAChR activation increased IL-10 expression in macrophages, independent of HO-1 expression. It is possible that the enhanced IL-10 expression in macrophages by a7nAChR activation may promote $\mathrm{HO}-1$ expression in $\mathrm{CacO} 2$ cells in the co-culture system, consistent with a previous study[55]. Notably, a7nAChR activation increased IL-10 expression, dependent on STAT3 activity, in intestinal epithelial cells. Given that GST-21 treatment significantly up-regulated IL-22 expression the enhanced IL-10 expression by a7nAChR activation in intestinal epithelial cells is likely mediated by IL-22related STAT3 activation or IL-10 autocrine-enhancement. It was unlike from IL-6-mediated SAT3 activation because $\mathrm{a} 7 \mathrm{nAChR}$ activation dramatically down-regulated the LPS-induced IL- 6 production in epithelial cells and macrophages. Our data disagree with the fact that inhibition of STAT3 phosphorylation can reduce inflammatory responses $[56,57]$. The discrepancy may stem from varying experimental conditions between us and those of others. Nevertheless, the increased anti-inflammatory cytokines and HO-1 expression, together with decreased pro-inflammatory cytokines, preserved the intestinal barrier integrity and inhibited cholestatic liver injury.

Our previous RNA-seq data revealed the differentially expressed genes in LPS-induced Caco-2 cells were enriched in the STAT3 signaling (Figure S4). In the present study, activation of a7nAChR enhanced STAT3 and AKT phosphorylation but attenuated NF-kBp65 activation in intestinal tissues and epithelial cells in a HO-1 dependent manner because HO-1 silencing or HO-1 knockout dramatically mitigated or abrogated the GST-21-enhanced STAT3 and AKT phosphorylation and GST-21-21-decreased NF-kBp65 activation in intestinal tissues and epithelial cells, consistent with a previous observation[58]. The HO-1 dependence may stem from its antioxidant activity to attenuate the NF-kB activation or enhanced IL-10 and IL-22 expression to promote STAT3 activation. In addition, activated STAT3 can promote ZO-1 and Occludin expression and reduce the intestinal barrier permeability $[59,60]$. Thus, our findings extended previous observations and may provide new insights into the regulation of a $7 \mathrm{nAChR}$ on $\mathrm{HO}-1$ expression and the STAT3 signaling in intestinal tissues during the pathogenic process of cholestatic liver injury. 
It was notable that inhibition of the PI3K/AKT signaling did not significantly modulate the HO-1 expression, but did significantly decreased the GST-21-enhanced STAT3 phosphorylation, and increased the NF-kBp65 activation in the LPS-treated intestinal epithelial cells. In contrast, inhibition of the $\mathrm{PI} 3 \mathrm{~K} / \mathrm{AKT}$ signaling did slightly reduce HO-1 expression and did not affect STAT3 phosphorylation although it did significantly enhance the NF-kBp65 activation in intestinal tissues of BDL mice in a HO-1 dependent manner. The difference may stem from a strong stimulation in vitro experimental system, which caused the minor cellular injury. Apparently, the activated STAT3 signaling may cross-talk with the $\mathrm{PI3K} / \mathrm{AKT}$ signaling to promote the survival of intestinal epithelial cells. Therefore, the HO-1/STAT3 signaling may be critical for preserving the intestinal barrier integrity while the PI3K/AKT may have moderate activity during the pathogenic process of cholestatic liver injury.

We recognized our studies had limitations. First, GTS-21, one of the most specific a7nAChR agonists, may be a concern for its clinical application so that discovery of newly safe agonists is urgently needed. Second, it remains to be determined how a7nAChR activation induces IL-10 and HO-1 expression in intestinal epithelial cells during the process of cholestatic liver injury. Lastly, a7nAChR activation significantly up-regulated the LPS-stimulated IL-22 expression in macrophages. However, it is unclear whether and how the up-regulated IL-22 expression contributes to protection from the BDL-damaged intestinal barrier and inflammation during the process of cholestatic liver injury[61, 62].

\section{Conclusions}

Our data highlighted that $a 7 n A C h R$ activation inhibited intestinal and systemic inflammation, intestinal and liver injury to preserve the intestinal barrier integrity in BDL mice and intestinal epithelial cells cocultured with macrophages. Mechanistically, a7nAChR activation enhanced the H0-1 expression, STAT3 and AKT phosphorylation, but decreased NF-kBp65 activation in intestinal tissues of BDL mice and LPStreated epithelial cells. The enhanced HO-1 expression and STAT3 activation were interdependent in intestinal tissues of BDL mice and LPS-treated epithelial cells. Accordingly, the HO-1/SATA3 signaling may be crucial for $\mathrm{A7nAChR}$ activation to preserve intestinal barrier integrity and inhibit the pathogenic process of cholestatic liver injury in mice. Therefore, our findings may provide new mechanisms underlying the action of a7nAChR activation in inhibiting cholestatic liver injury and uncover that a7nAChR may be a therapeutic target for the intervention of PBC.

\section{Abbreviations}

Bile Duct Ligation

BDL,a7 Nicotinic Acetylcholine Receptor:a7nAChR, Primary Biliary Cholangitis:PBC, Cholinergic AntiInflammatory Pathway:CAP, Nicotinic Acetylcholine Receptors:nAChRs, Acetylcholine:ACh, Nuclear Factor Erythrocyte-Associated Factor 2:NRF2, Alanine aminotransferase:ALT, Aspartate transaminase:AST, Hematoxylin and Eosin:H\&E, Transepithelial Electrical Resistance:TEER, FITC-dextran-4:FD4, Sodium Dodecyl Sulfate Polyacrylamide Gel Electrophoresis:SDS-PAGE. 


\section{Declarations}

\section{Acknowledgements}

We would like to thank Professor Dong Shang and Professor Hui-shu Guo of the hospital for providing the laboratory.

\section{Authors' contributions}

Wei Lei designed and participated in the completion of the whole experiment, analyzed the data and wrote the manuscript. Changcheng Zhao completed part of Western Blot and assisted in animal experiments, Jiasen Sun was responsible for all the ELISA and part of the experimental data analysis, and Yanling Jin was responsible for the H\&E staining experiment. Zhijun Duan reviewed the final manuscript. All authors read and approved the final manuscript.

\section{Funding Sources}

No funding was received for this study.

\section{Availability of data and materials}

Not applicable

\section{Declarations}

\section{Ethics approval and consent to participate}

The study was approved by the Ethics Committee of Dalian Medical University, Huazhong University of Science and Technology (approval ID AEE19011).

\section{Consent for publication}

Not applicable.

\section{Competing interests}

The authors declare that no competing interests exist.

\section{Author details}

${ }^{1}$ Second Department of Gastroenterology, The First Affiliated Hospital of Dalian Medical University, Dalian 116044, China

${ }^{2}$ Laboratory of integrated Chinese and western medicine, The First Affiliated Hospital of Dalian Medical University, Dalian 116044, China 
${ }^{3}$ Pathology Department, The First Affiliated Hospital of Dalian Medical University, Dalian 116044, China

\section{References}

1. European Association for the Study of the Liver. Electronic address eee, European Association for the Study of the L: EASL Clinical Practice Guidelines: The diagnosis and management of patients with primary biliary cholangitis. J Hepatol. 2017;67:145-72.

2. Karlsen TH, Folseraas T, Thorburn D, Vesterhus M. Primary sclerosing cholangitis - a comprehensive review. J Hepatol. 2017;67:1298-323.

3. Pereira P, Aho V, Arola J, Boyd S, Jokelainen K, Paulin L, Auvinen P, Farkkila M. Bile microbiota in primary sclerosing cholangitis: Impact on disease progression and development of biliary dysplasia. PLoS One. 2017;12:e0182924.

4. Ohtani N, Kawada N. Role of the Gut-Liver Axis in Liver Inflammation, Fibrosis, and Cancer: A Special Focus on the Gut Microbiota Relationship. Hepatol Commun. 2019;3:456-70.

5. Hurst R, Rollema H, Bertrand D. Nicotinic acetylcholine receptors: from basic science to therapeutics. Pharmacol Ther. 2013;137:22-54.

6. Corradi J, Bouzat C. Understanding the Bases of Function and Modulation of alpha7 Nicotinic Receptors: Implications for Drug Discovery. Mol Pharmacol. 2016;90:288-99.

7. Tracey KJ. Reflex control of immunity. Nat Rev Immunol. 2009;9:418-28.

8. Ren C, Tong YL, Li JC, Lu ZQ, Yao YM. The Protective Effect of Alpha 7 Nicotinic Acetylcholine Receptor Activation on Critical Illness and Its Mechanism. Int J Biol Sci. 2017;13:46-56.

9. Borovikova LV, Ivanova S, Zhang M, Yang H, Botchkina GI, Watkins LR, Wang H, Abumrad N, Eaton JW, Tracey KJ. Vagus nerve stimulation attenuates the systemic inflammatory response to endotoxin. Nature. 2000;405:458-62.

10. Wang H, Yu M, Ochani M, Amella CA, Tanovic M, Susarla S, Li JH, Wang H, Yang H, Ulloa L, et al. Nicotinic acetylcholine receptor alpha7 subunit is an essential regulator of inflammation. Nature. 2003;421:384-8.

11. Meroni E, Stakenborg N, Viola MF, Boeckxstaens GE. Intestinal macrophages and their interaction with the enteric nervous system in health and inflammatory bowel disease. Acta Physiol (Oxf). 2019;225:e13163.

12. Foucault-Fruchard L, Tronel C, Bodard S, Gulhan Z, Busson J, Chalon S, Antier D. Alpha-7 nicotinic acetylcholine receptor agonist treatment in a rat model of Huntington's disease and involvement of heme oxygenase-1. Neural Regen Res. 2018;13:737-41.

13. van Maanen MA, Stoof SP, van der Zanden EP, de Jonge WJ, Janssen RA, Fischer DF, Vandeghinste $\mathrm{N}$, Brys R, Vervoordeldonk MJ, Tak PP. The alpha7 nicotinic acetylcholine receptor on fibroblast-like synoviocytes and in synovial tissue from rheumatoid arthritis patients: a possible role for a key neurotransmitter in synovial inflammation. Arthritis Rheum. 2009;60:1272-81. 
14. Kox M, Pompe JC, Peters E, Vaneker M, van der Laak JW, van der Hoeven JG, Scheffer GJ, Hoedemaekers CW, Pickkers P. alpha7 nicotinic acetylcholine receptor agonist GTS-21 attenuates ventilator-induced tumour necrosis factor-alpha production and lung injury. $\mathrm{Br} \mathrm{J}$ Anaesth. 2011;107:559-66.

15. Jensen K, Afroze S, Ueno Y, Rahal K, Frenzel A, Sterling M, Guerrier M, Nizamutdinov D, Dostal DE, Meng F, Glaser SS. Chronic nicotine exposure stimulates biliary growth and fibrosis in normal rats. Dig Liver Dis. 2013;45:754-61.

16. Kawamata J, Shimohama S. Stimulating nicotinic receptors trigger multiple pathways attenuating cytotoxicity in models of Alzheimer's and Parkinson's diseases. J Alzheimers Dis. 2011;24(Suppl 2):95-109.

17. Subramaniam A, Shanmugam MK, Perumal E, Li F, Nachiyappan A, Dai X, Swamy SN, Ahn KS, Kumar AP, Tan BK, et al. Potential role of signal transducer and activator of transcription (STAT)3 signaling pathway in inflammation, survival, proliferation and invasion of hepatocellular carcinoma. Biochim Biophys Acta. 2013;1835:46-60.

18. Takeda K, Clausen BE, Kaisho T, Tsujimura T, Terada N, Forster I, Akira S. Enhanced Th1 activity and development of chronic enterocolitis in mice devoid of Stat3 in macrophages and neutrophils. Immunity. 1999;10:39-49.

19. Cui WY, Li MD. Nicotinic modulation of innate immune pathways via alpha7 nicotinic acetylcholine receptor. J Neuroimmune Pharmacol. 2010;5:479-88.

20. Egea J, Buendia I, Parada E, Navarro E, Leon R, Lopez MG. Anti-inflammatory role of microglial alpha7 nAChRs and its role in neuroprotection. Biochem Pharmacol. 2015;97:463-72.

21. Ottani A, Giuliani D, Neri L, Calevro A, Canalini F, Vandini E, Cainazzo MM, Ruberto IA, Barbieri A, Rossi R, Guarini S. NDP-alpha-MSH attenuates heart and liver responses to myocardial reperfusion via the vagus nerve and JAK/ERK/STAT signaling. Eur J Pharmacol. 2015;769:22-32.

22. Du MH, Luo HM, Hu S, Lv Y, Lin ZL, Ma L. Electroacupuncture improves gut barrier dysfunction in prolonged hemorrhagic shock rats through vagus anti-inflammatory mechanism. World $\mathrm{J}$ Gastroenterol. 2013;19:5988-99.

23. Torres-Rosas R, Yehia G, Pena G, Mishra P, del Rocio Thompson-Bonilla M, Moreno-Eutimio MA, Arriaga-Pizano LA, Isibasi A, Ulloa L. Dopamine mediates vagal modulation of the immune system by electroacupuncture. Nat Med. 2014;20:291-5.

24. Stakenborg N, Labeeuw E, Gomez-Pinilla PJ, De Schepper S, Aerts R, Goverse G, Farro G, Appeltans I, Meroni E, Stakenborg M, et al. Preoperative administration of the 5-HT4 receptor agonist prucalopride reduces intestinal inflammation and shortens postoperative ileus via cholinergic enteric neurons. Gut. 2019;68:1406-16.

25. Tsoyi K, Jang HJ, Kim JW, Chang HK, Lee YS, Pae HO, Kim HJ, Seo HG, Lee JH, Chung HT, Chang KC. Stimulation of alpha7 nicotinic acetylcholine receptor by nicotine attenuates inflammatory response in macrophages and improves survival in experimental model of sepsis through heme oxygenase-1 induction. Antioxid Redox Signal. 2011;14:2057-70. 
26. Zhang L, Zhang Z, Liu B, Jin Y, Tian Y, Xin Y, Duan Z. The Protective Effect of Heme Oxygenase-1 against Intestinal Barrier Dysfunction in Cholestatic Liver Injury Is Associated with NF-kappaB Inhibition. Mol Med. 2017;23:215-24.

27. Sintiprungrat K, Singhto N, Sinchaikul S, Chen ST, Thongboonkerd V. Alterations in cellular proteome and secretome upon differentiation from monocyte to macrophage by treatment with phorbol myristate acetate: insights into biological processes. J Proteomics. 2010;73:602-18.

28. Taggart CC, Cryan SA, Weldon S, Gibbons A, Greene CM, Kelly E, Low TB, O'Neill SJ, McElvaney NG. Secretory leucoprotease inhibitor binds to NF-kappaB binding sites in monocytes and inhibits p65 binding. J Exp Med. 2005;202:1659-68.

29. Lissner D, Schumann M, Batra A, Kredel LI, Kuhl AA, Erben U, May C, Schulzke JD, Siegmund B. Monocyte and M1 Macrophage-induced Barrier Defect Contributes to Chronic Intestinal Inflammation in IBD. Inflamm Bowel Dis. 2015;21:1297-305.

30. Li J, Mizukami Y, Zhang X, Jo WS, Chung DC. Oncogenic K-ras stimulates Wnt signaling in colon cancer through inhibition of GSK-3beta. Gastroenterology. 2005;128:1907-18.

31. Schust J, Sperl B, Hollis A, Mayer TU, Berg T. Stattic: a small-molecule inhibitor of STAT3 activation and dimerization. Chem Biol. 2006;13:1235-42.

32. Ljubuncic P, Tanne Z, Bomzon A. Evidence of a systemic phenomenon for oxidative stress in cholestatic liver disease. Gut. 2000;47:710-6.

33. Wang Y, Aoki H, Yang J, Peng K, Liu R, Li X, Qiang X, Sun L, Gurley EC, Lai G, et al. The role of sphingosine 1-phosphate receptor 2 in bile-acid-induced cholangiocyte proliferation and cholestasisinduced liver injury in mice. Hepatology. 2017;65:2005-18.

34. Jiang H, Liu X, Knolhoff BL, Hegde S, Lee KB, Jiang H, Fields RC, Pachter JA, Lim KH, DeNardo DG. Development of resistance to FAK inhibition in pancreatic cancer is linked to stromal depletion. Gut. 2020;69:122-32.

35. Li S, Yi Z, Deng M, Scott MJ, Yang C, Li W, Lei Z, Santerre NM, Loughran P, Billiar TR. TSLP protects against liver I/R injury via activation of the PI3K/Akt pathway. JCI Insight 2019, 4.

36. Chiu CJ, McArdle AH, Brown R, Scott HJ, Gurd FN. Intestinal mucosal lesion in low-flow states. I. A morphological, hemodynamic, and metabolic reappraisal. Arch Surg. 1970;101:478-83.

37. Cai SY, Ouyang X, Chen Y, Soroka CJ, Wang J, Mennone A, Wang Y, Mehal WZ, Jain D, Boyer JL. Bile acids initiate cholestatic liver injury by triggering a hepatocyte-specific inflammatory response. $\mathrm{JCI}$ Insight. 2017;2:e90780.

38. Albillos A, de Gottardi A, Rescigno M. The gut-liver axis in liver disease: Pathophysiological basis for therapy. J Hepatol. 2020;72:558-77.

39. Zhang Y, Hong JY, Rockwell CE, Copple BL, Jaeschke H, Klaassen CD. Effect of bile duct ligation on bile acid composition in mouse serum and liver. Liver Int. 2012;32:58-69.

40. Geier A, Dietrich CG, Voigt S, Kim SK, Gerloff T, Kullak-Ublick GA, Lorenzen J, Matern S, Gartung C. Effects of proinflammatory cytokines on rat organic anion transporters during toxic liver injury and cholestasis. Hepatology. 2003;38:345-54. 
41. Frissen M, Liao L, Schneider KM, Djudjaj S, Haybaeck J, Wree A, Rolle-Kampczyk U, von Bergen M, Latz E, Boor P, Trautwein C. Bidirectional Role of NLRP3 During Acute and Chronic Cholestatic Liver Injury. Hepatology. 2021;73:1836-54.

42. Yao JH, Zhang XS, Zheng SS, Li YH, Wang LM, Wang ZZ, Chu L, Hu XW, Liu KX, Tian XF. Prophylaxis with carnosol attenuates liver injury induced by intestinal ischemia/reperfusion. World $\mathrm{J}$ Gastroenterol. 2009;15:3240-5.

43. Clements WD, Parks R, Erwin P, Halliday MI, Barr J, Rowlands BJ. Role of the gut in the pathophysiology of extrahepatic biliary obstruction. Gut. 1996;39:587-93.

44. Parikh K, Antanaviciute A, Fawkner-Corbett D, Jagielowicz M, Aulicino A, Lagerholm C, Davis S, Kinchen J, Chen $\mathrm{HH}$, Alham NK, et al. Colonic epithelial cell diversity in health and inflammatory bowel disease. Nature. 2019;567:49-55.

45. Zhang Y, Zhou F, Wang Z, Li Z, Li J. PNU-282987 Attenuates Intestinal Epithelial Barrier Dysfunction in LPS-Induced Endotoxemia. Inflammation. 2020;43:417-24.

46. Nishitani Y, Yamamoto K, Yoshida M, Azuma T, Kanazawa K, Hashimoto T, Mizuno M. Intestinal antiinflammatory activity of luteolin: role of the aglycone in NF-kappaB inactivation in macrophages cocultured with intestinal epithelial cells. Biofactors. 2013;39:522-33.

47. Pinheiro NM, Santana FP, Almeida RR, Guerreiro M, Martins MA, Caperuto LC, Camara NO, Wensing LA, Prado VF, Tiberio IF, et al. Acute lung injury is reduced by the alpha7nAChR agonist PNU-282987 through changes in the macrophage profile. FASEB J. 2017;31:320-32.

48. Li B, Wu J, Bao J, Han X, Shen S, Ye X, Dai J, Wu Z, Niu M, He Y, et al. Activation of alpha7nACh receptor protects against acute pancreatitis through enhancing TFEB-regulated autophagy. Biochim Biophys Acta Mol Basis Dis. 2020;1866:165971.

49. Ngo VL, Abo H, Maxim E, Harusato A, Geem D, Medina-Contreras O, Merlin D, Gewirtz AT, Nusrat A, Denning TL. A cytokine network involving IL-36gamma, IL-23, and IL-22 promotes antimicrobial defense and recovery from intestinal barrier damage. Proc Natl Acad Sci U S A. 2018;115:E5076-85.

50. Wei HX, Wang B, Li B. IL-10 and IL-22 in Mucosal Immunity: Driving Protection and Pathology. Front Immunol. 2020;11:1315.

51. Martinez-Lopez M, Iborra S, Conde-Garrosa R, Mastrangelo A, Danne C, Mann ER, Reid DM, GaboriauRouthiau V, Chaparro M, Lorenzo MP, et al. Microbiota Sensing by Mincle-Syk Axis in Dendritic Cells Regulates Interleukin-17 and - 22 Production and Promotes Intestinal Barrier Integrity. Immunity. 2019;50:446-61 e449.

52. Zhang Z, Zhang Q, Li F, Xin Y, Duan Z. Contributions of HO-1-Dependent MAPK to Regulating Intestinal Barrier Disruption. Biomol Ther (Seoul). 2021;29:175-83.

53. Cho RL, Lin WN, Wang CY, Yang CC, Hsiao LD, Lin CC, Yang CM. Heme oxygenase-1 induction by rosiglitazone via PKCalpha/AMPKalpha/p38 MAPKalpha/SIRT1/PPARgamma pathway suppresses lipopolysaccharide-mediated pulmonary inflammation. Biochem Pharmacol. 2018;148:222-37.

54. Sallam MY, El-Gowilly SM, El-Gowelli HM, El-Lakany MA, El-Mas MM. Additive counteraction by alpha7 and alpha4beta2-nAChRs of the hypotension and cardiac sympathovagal imbalance evoked 
by endotoxemia in male rats. Eur J Pharmacol. 2018;834:36-44.

55. Marelli G, Erreni M, Anselmo A, Taverniti V, Guglielmetti S, Mantovani A, Allavena P. Heme-oxygenase1 Production by Intestinal CX3CR1(+) Macrophages Helps to Resolve Inflammation and Prevents Carcinogenesis. Cancer Res. 2017;77:4472-85.

56. Liu Y, Liu L, Zhou Y, Zhou P, Yan Q, Chen X, Ding S, Zhu F. CKLF1 Enhances Inflammation-Mediated Carcinogenesis and Prevents Doxorubicin-Induced Apoptosis via IL6/STAT3 Signaling in HCC. Clin Cancer Res. 2019;25:4141-54.

57. Braun DA, Fribourg M, Sealfon SC. Cytokine response is determined by duration of receptor and signal transducers and activators of transcription 3 (STAT3) activation. J Biol Chem.

2013;288:2986-93.

58. Wang Z, Li R, Tan J, Peng L, Wang P, Liu J, Xiong H, Jiang B, Chen Y. Syndecan-1 Acts in Synergy with Tight Junction Through Stat3 Signaling to Maintain Intestinal Mucosal Barrier and Prevent Bacterial Translocation. Inflamm Bowel Dis. 2015;21:1894-907.

59. Han D, Chen W, Gu X, Shan R, Zou J, Liu G, Shahid M, Gao J, Han B. Cytoprotective effect of chlorogenic acid against hydrogen peroxide-induced oxidative stress in MC3T3-E1 cells through PI3K/Akt-mediated Nrf2/HO-1 signaling pathway. Oncotarget. 2017;8:14680-92.

60. Chaurasia B, Mauer J, Koch L, Goldau J, Kock AS, Bruning JC. Phosphoinositide-dependent kinase 1 provides negative feedback inhibition to Toll-like receptor-mediated NF-kappaB activation in macrophages. Mol Cell Biol. 2010;30:4354-66.

61. Zhou X, Qi W, Hong T, Xiong T, Gong D, Xie M, Nie S. Exopolysaccharides from Lactobacillus plantarum NCU116 Regulate Intestinal Barrier Function via STAT3 Signaling Pathway. J Agric Food Chem. 2018;66:9719-27.

62. Fang $Y$, Wu C, Wang Q, Tang J. Farnesol contributes to intestinal epithelial barrier function by enhancing tight junctions via the JAK/STAT3 signaling pathway in differentiated Caco-2 cells. J Bioenerg Biomembr. 2019;51:403-12.

\section{Figures}


a
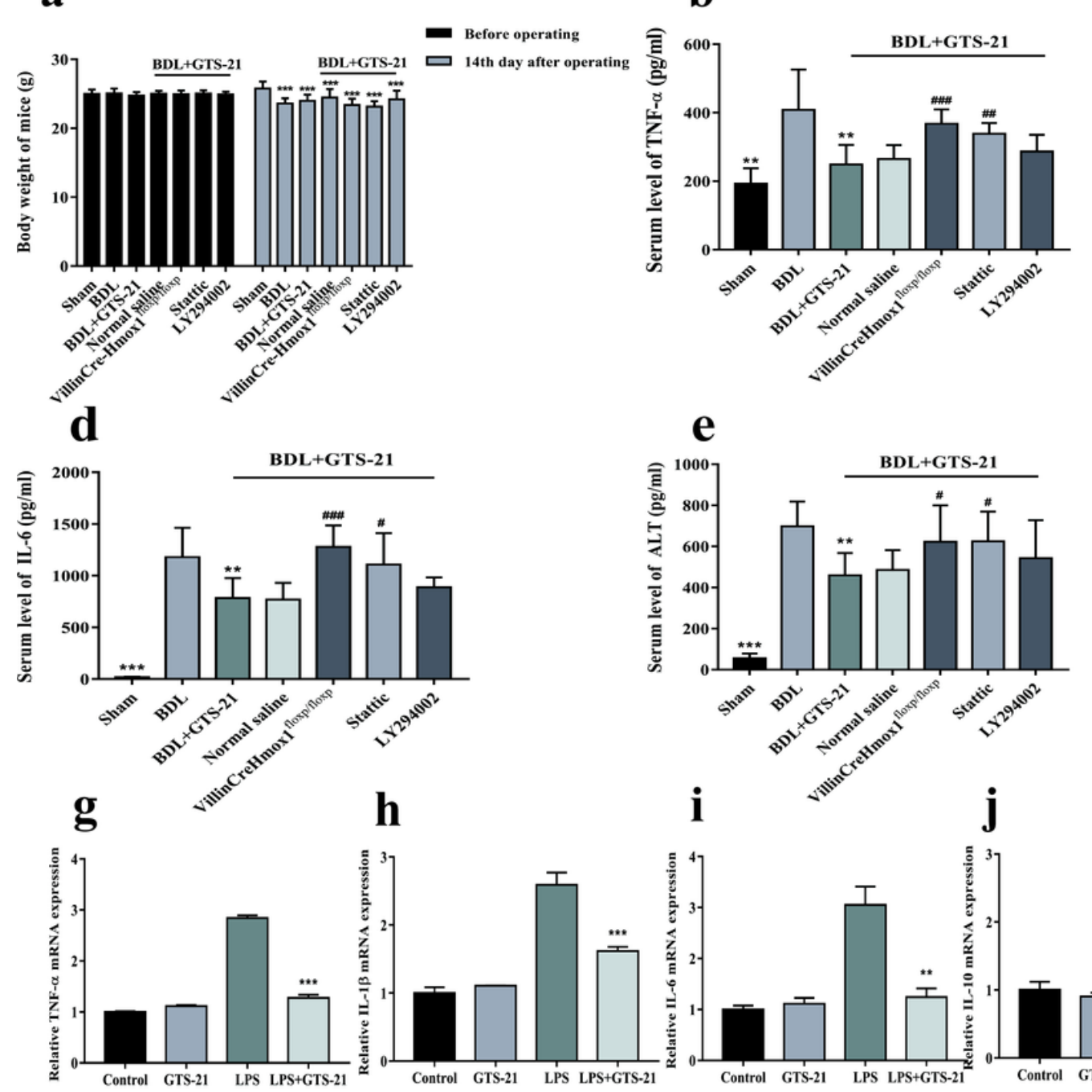

l
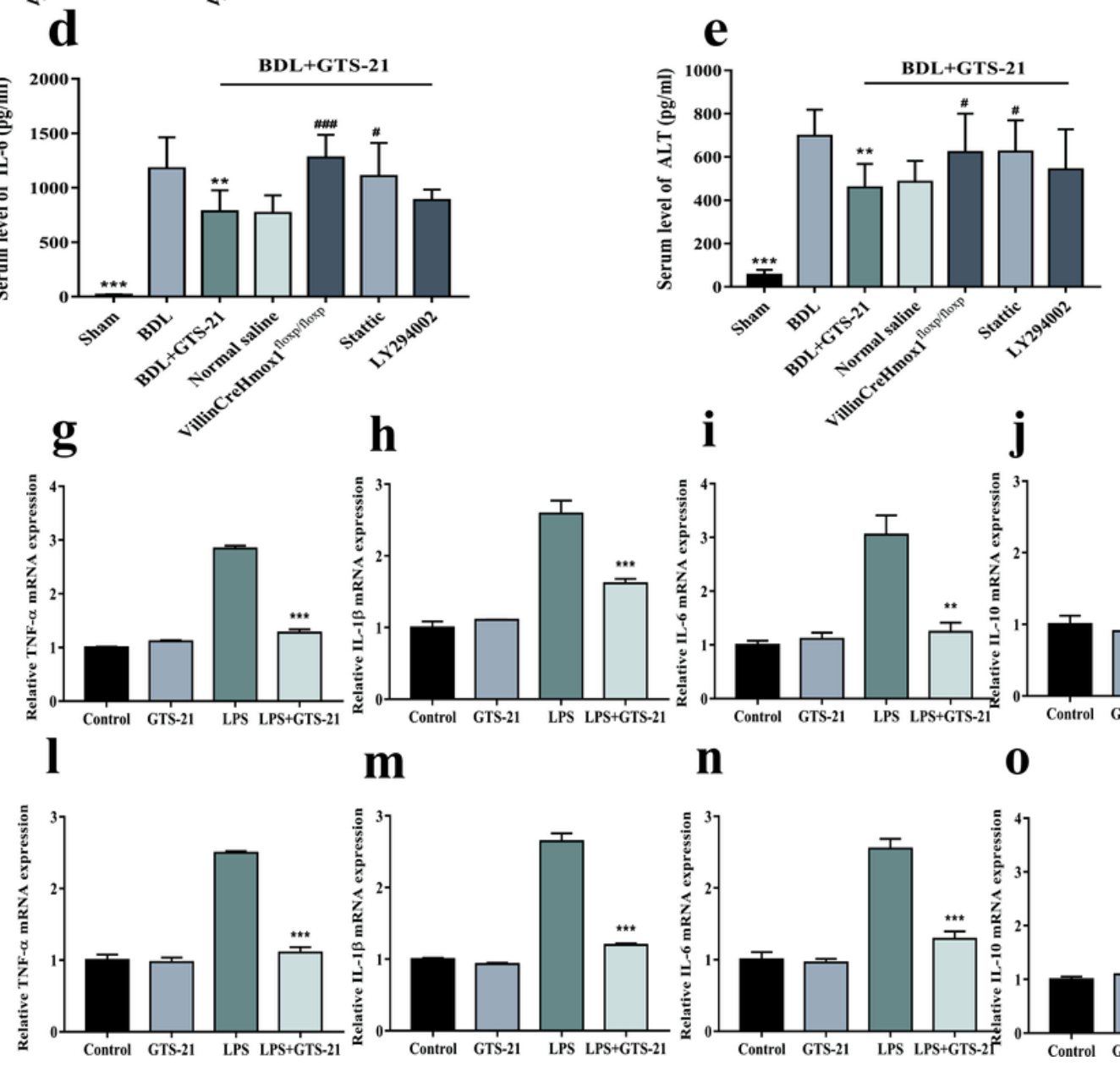

h

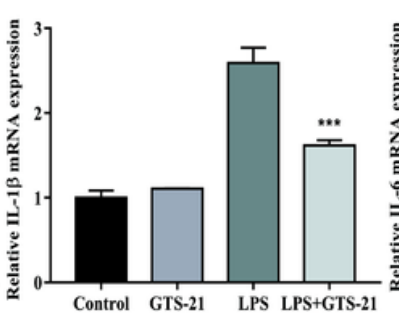

$\mathbf{m}$

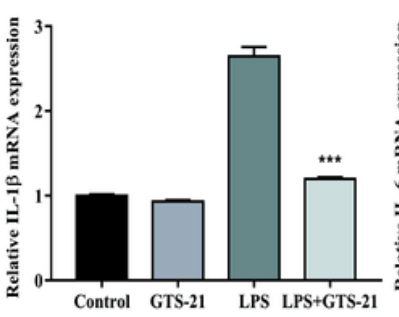

b

c
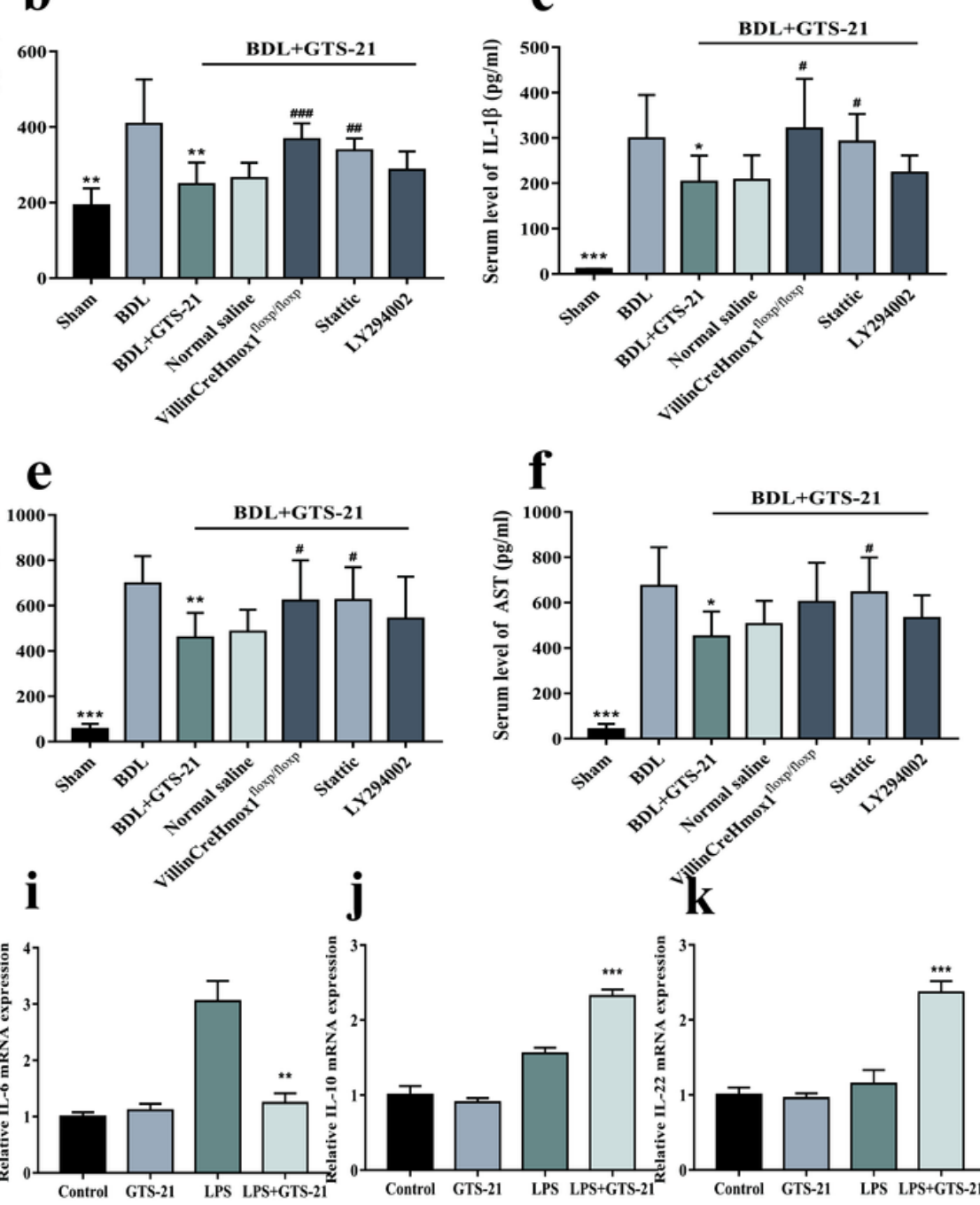

n

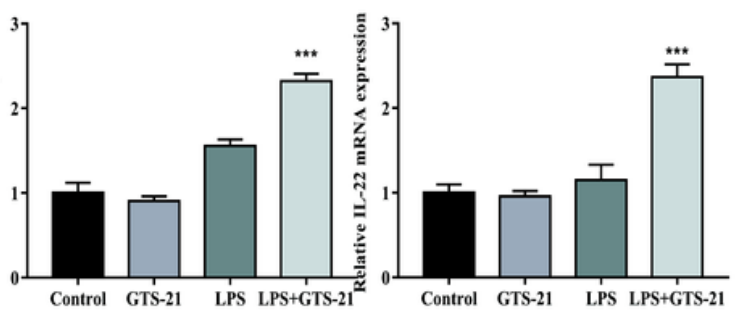

o

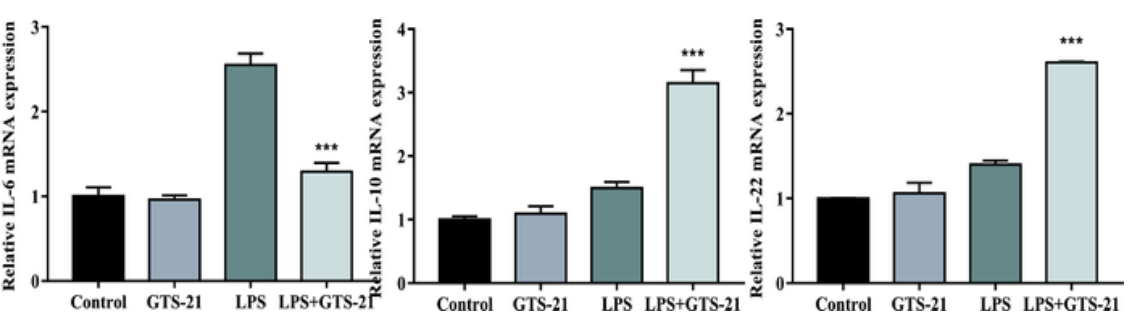

Figure 1

Activating a7nAChR by GST-21 inhibits inflammation and preserves liver function in BDL mice. (a) Body weight changes in each group of mice were measured before and on day 14th post BDL ( $n=6-8$ mice in each group). (b-d) The levels of serum TNF-a, IL-1 $\beta$ and IL-6. (e-f) The levels of serum ALT and AST. *P $<$

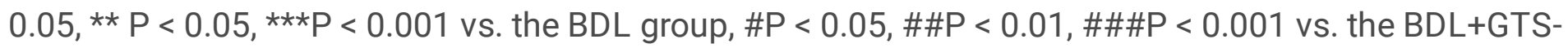
21 group. (g-p) RT-PCR analysis of the relative levels of TNF-a, IL-1 $\beta$, IL-6, IL-10 and IL-22 to $\beta$-actin mRNA transcripts in U937(g-k) and RAW264.7(l-p) macrophages ( $n=3$ in each group). ** $P<0.01$, ${ }^{\star \star *} P<0.001$ vs. the LPS group. 
a
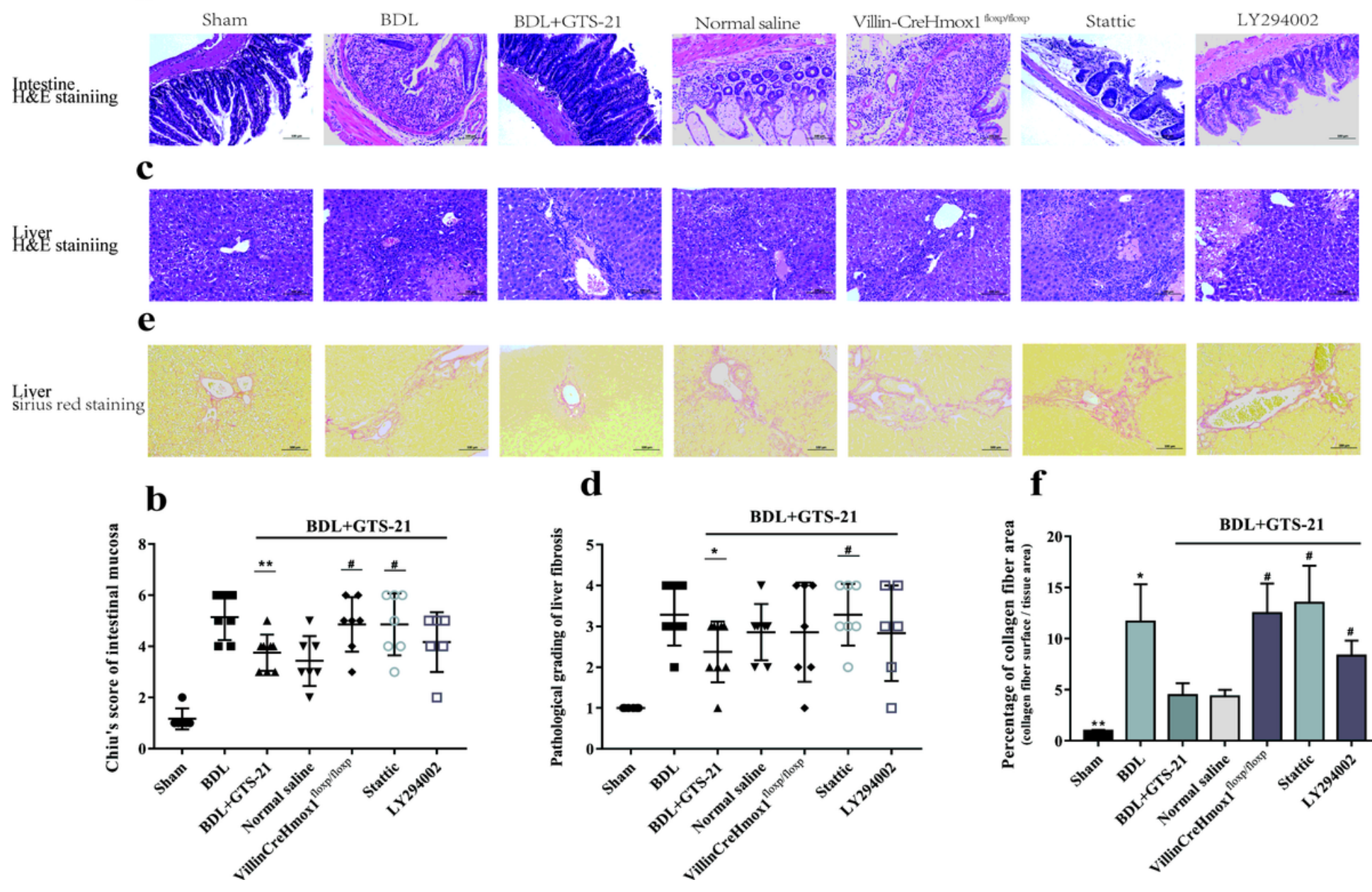

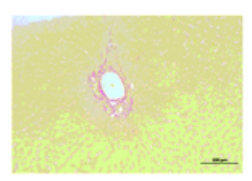

d

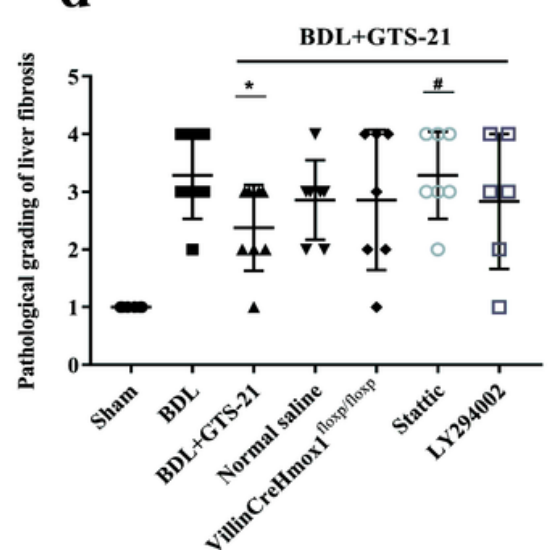

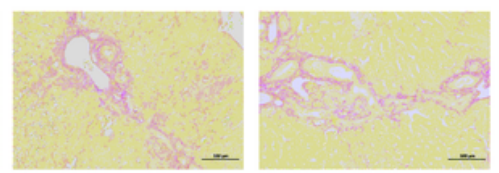

\section{f}

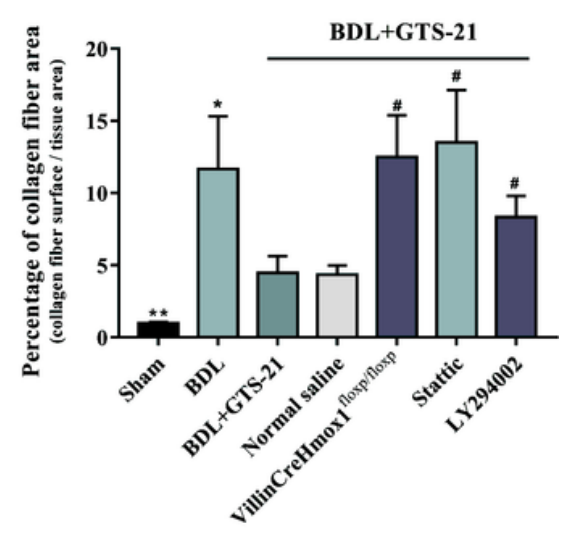

Figure 2

Activating a7nAChR ameliorates intestinal mucosal damage and liver fibrosis in BDL mice. (a) hematoxylin and eosin (H\&E) staining of intestinal tissue sections (200x, scale bar $=100 \mu \mathrm{m}, \mathrm{n}=3)$. (b) Chiu's scores of intestinal mucosal damages in each group of mice. (c) H\&E staining of liver fibrosis in each group of mice $(200 x$, scale bar $=100 \mu \mathrm{m}, \mathrm{n}=3)$. (d) Pathological grades of liver fibrosis in each group of mice. (e) Sirius Red staining analysis of collagen deposition in the liver of each group of mice $(200 x$, scale bar $=100 \mu \mathrm{m}, \mathrm{n}=3)$. (f) Quantitative analysis of collagen contents in the liver of each group of mice. ${ }^{*}<<0.05,{ }^{\star *} P<0.01,{ }^{\star} * * P<0.001$ vs. the $B D L$ group, $\# P<0.05, \# \# P<0.01, \# \# \# P<0.001$ vs. the $B D L+G T S-21$ group. 
a

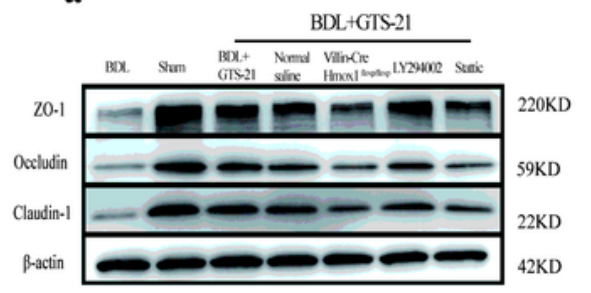

b

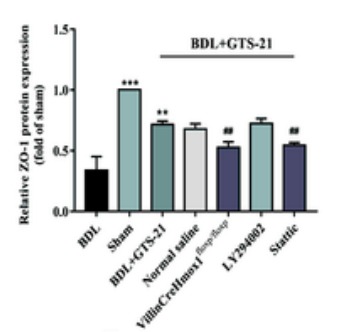
g

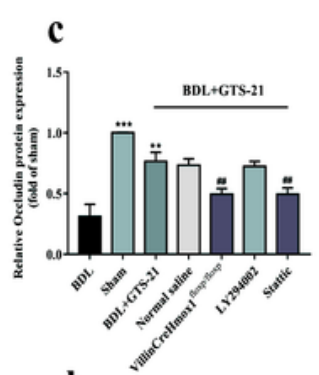

h

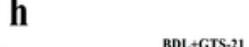

souctiss

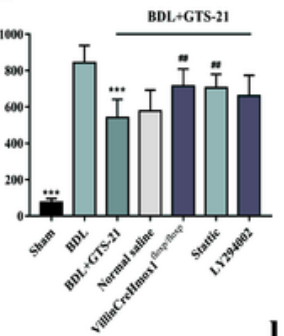

d

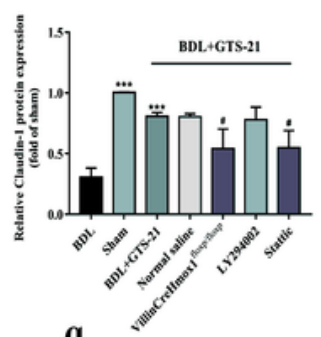

q

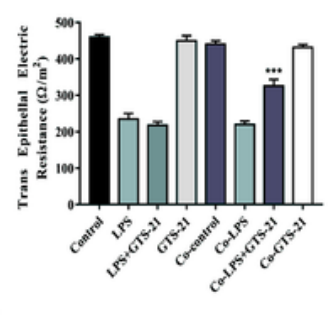

i
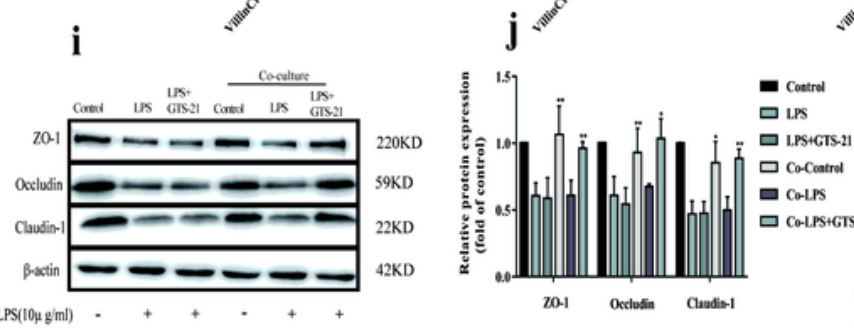

$\mathrm{k}$

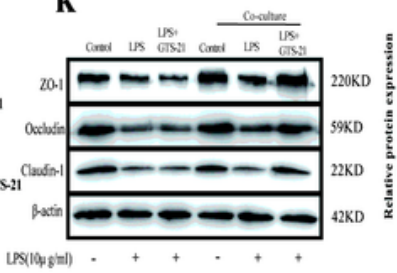

l

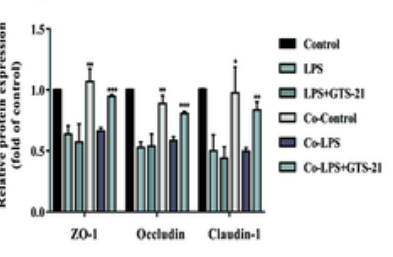

LPS 100,

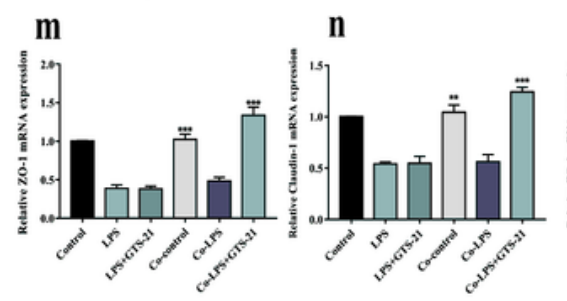

0 p

t
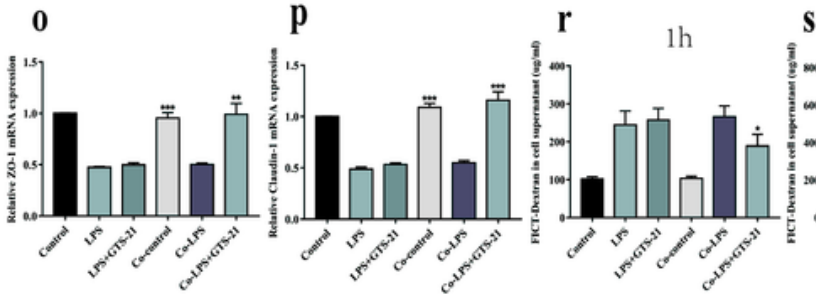

s $3 \mathrm{~h}$

$3 \mathrm{~h}$

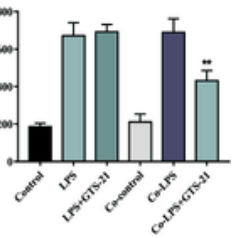

Co-culture

Control

LPS

LPS+GTS-21

Control

LPS

LPS+GTS-21

DAPI
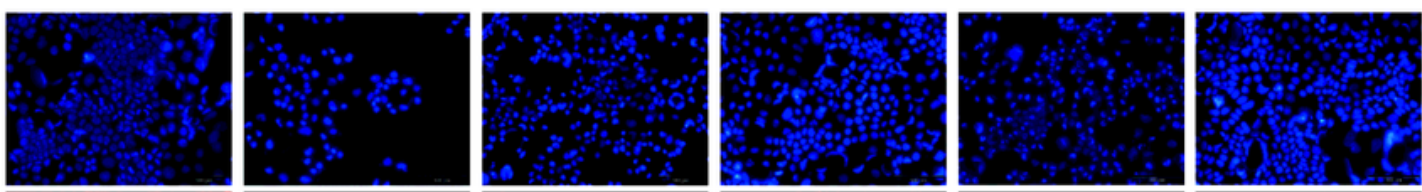

ZO-1
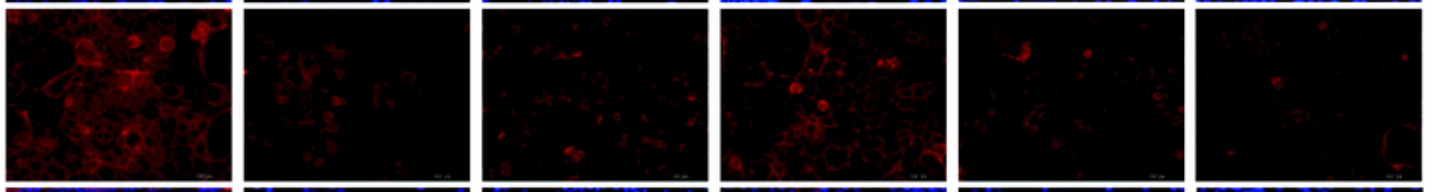

Merge
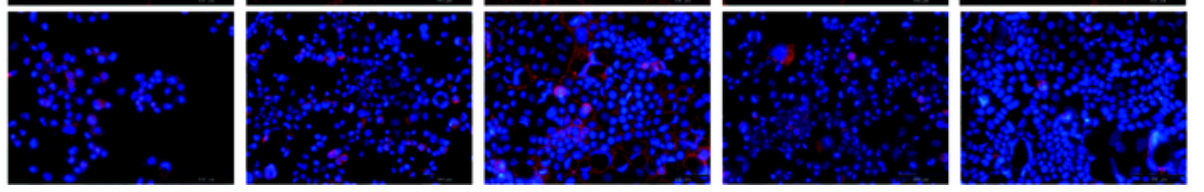

\section{Figure 3}

Activating a7nAChR preserves the expression of tight junction proteins and intestinal epithelial barrier integrity in vivo and in vitro. (a-d) Western blot analysis of the relative levels of ZO-1, Occludin and Claudin-1 expression in the intestinal epithelium of each group ( $n=3$ per group). (e-g) RT-PCR analysis of the relative levels of ZO-1, Occludin and Claudin-1 to the control $\beta$-actin mRNA transcripts in intestinal tissues of each group ( $\mathrm{n}=3$ pre group). (h) Fluorescent spectrometry analysis of serum FITC-dextran to 
determine the intestinal epithelial permeability in BDL mice following oral administration. ${ }^{\star} \mathrm{P}<0.01$, $* \star * P$ $<0.001$ vs. the $B D L$ group, $\# \mathrm{P}<0.05$, \#\#P $<0.01$, \#\#\#P< 0.001 vs. the $B D L+G T S-21$ group. (i-l) Western blot analysis of the relative levels of ZO-1, Occludin and Claudin-1 expression in Caco2(i-j) and HT29 cells $(k-1)$ ( $n=3$ pre group). (m-p) RT-PCR analysis of the relative levels of ZO-1 and Claudin- 1 to the control $\beta$-actin mRNA transcripts in Caco2(m-n) and HT29 cells (o-p) ( $n=3$ pre group). (q) The TEER in each group of Caco-2 monolayer ( $n=3)$. ( $r-s)$ Permeability of various groups of Caco-2 monolayer $(n=3)$. *P<0.05, ** $P$ $<0.01, \star \star * P<0.001$ vs. the Co-LPS group. ( $\mathrm{t}$ ) Immunofluorescence analysis of ZO-1 expression (200x, Bar $=100 \mu \mathrm{m})$ for ZO-1囚red) and nuclei were stained with DAPI (blue).
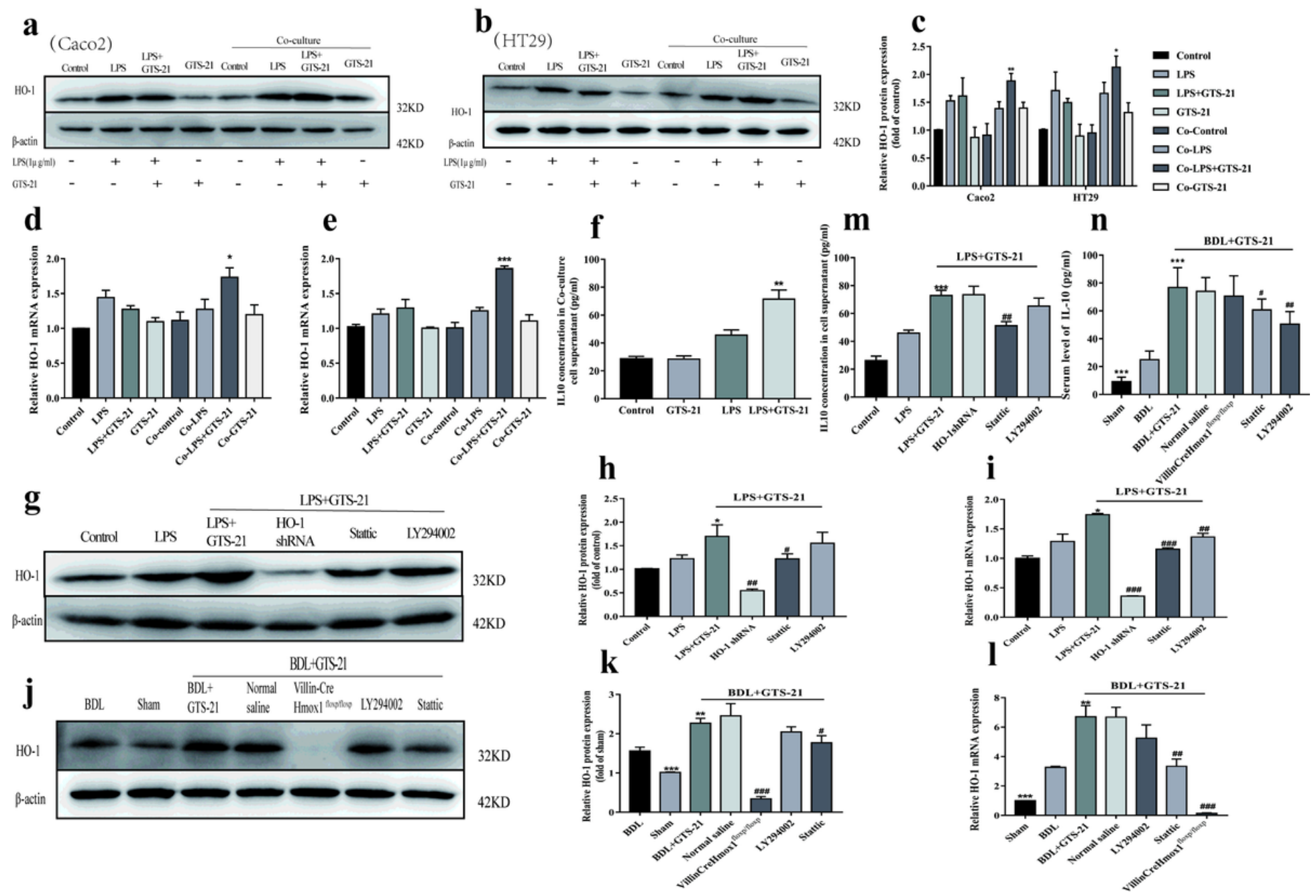

Figure 4

Activating a7nAChR enhances HO-1 expression in intestinal epithelial cells and tissues. (a-c) Western blot analysis of the relative levels of $\mathrm{HO}-1$ protein expression in Caco2 and HT29 cells ( $\mathrm{n}=3$ pre group). (d-e) RT-PCR analysis of the relative levels of HO-1 to the control $\beta$-actin mRNA transcripts in Caco2 and HT29 cells ( $n=3$ pre group). (f) ELISA analysis of the levels of IL-10 in the supernatants of co-cultured cells $(n=3$ per group). (g-i) Western blot and RT-qPCR analyses of the relative levels of HO-1 to the control $\beta$-actin expression in the indicated Caco-2 cells ( $n=3$ per group). ( $(-1)$ Western blot and RT-qPCR analyses of the relative levels of $\mathrm{HO}-1$ to the control $\beta$-actin expression in the intestinal tissues of mice ( $n=3$ per group). (m) ELISA analysis of the levels of IL-10 in the supernatants of co-cultured cells indicated ( $n=3$ per 
group). (n) ELISA analysis of the levels of serum IL-10 in each group of mice $(n=6-8)$. ${ }^{*} P<0.05$, $* * P<$ $0.05, * \star \star P<0.001$ vs. the LPS or BDL group. \#P $<0.05$, \#\#P<0.01, \#\#\#P<0.001 vs. the LPS+GTS-21 or BDL+GTS-21 group.
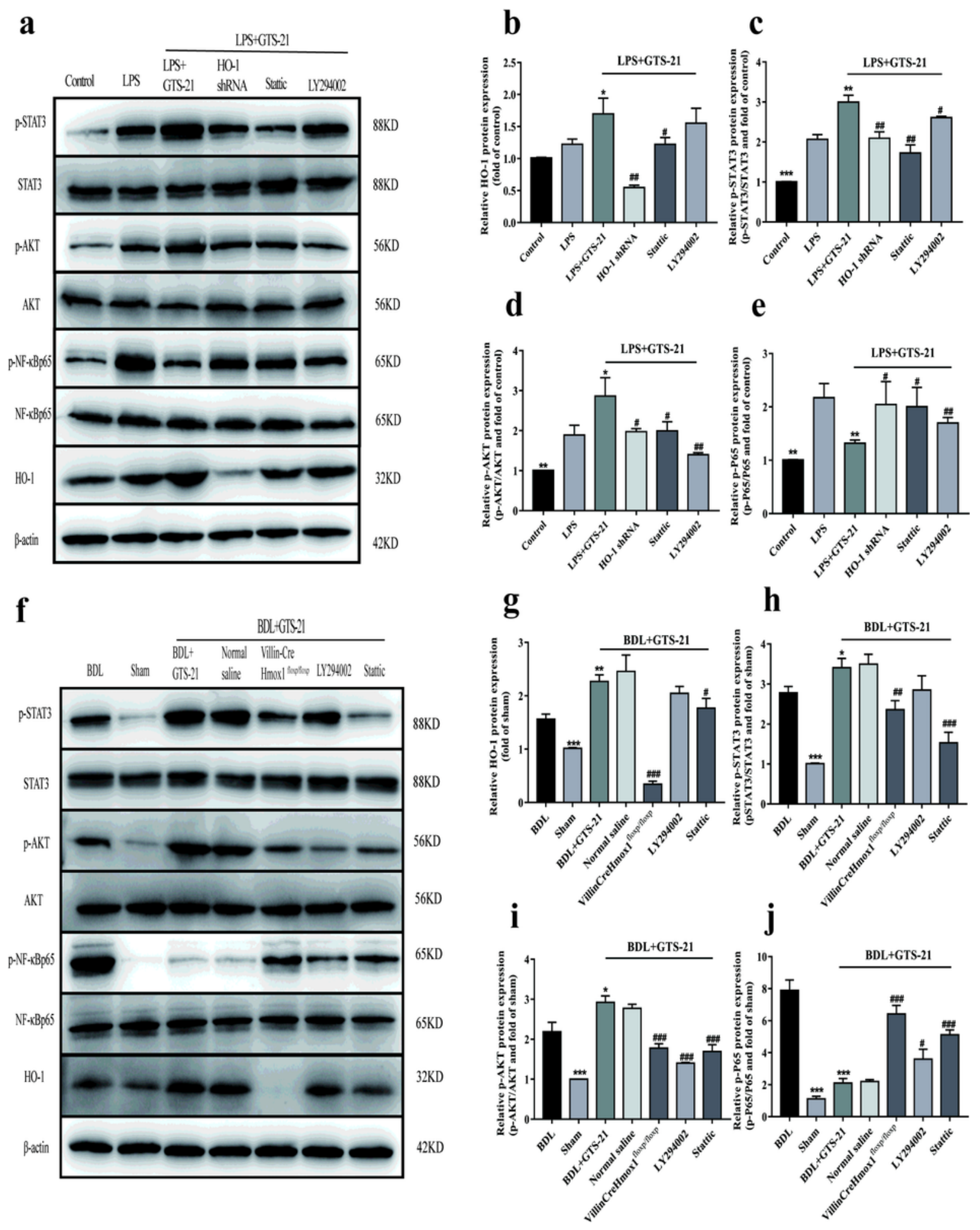

Figure 5

Activating a7nAChR enhances the HO-1/STAT3 and PI3K/AKT signaling to inhibit NF-KB activation in intestinal tissues of BDL mice. (a-e) Western blot and quantitative analysis of the relative levels of HO-1 
expression, STAT3, AKT and NF-kBp65 activation in the indicated Caco-2 cells ( $n=3$ per group). ( $f-j$ ) Western blot and quantitative analysis of the relative levels of HO-1 expression, STAT3, AKT and NFkBp65 activation in intestinal tissues of different groups of $B D L$ mice ( $n=3$ per group). ${ }^{*}<0.05$, $* \star P<$ $0.05, * \star * P<0.001$ vs. the LPS or BDL group. \#P $<0.05$, \#\#P $<0.01$, \#\#\#P $<0.001$ vs. the LPS+GTS-21 or BDL+GTS-21 group.

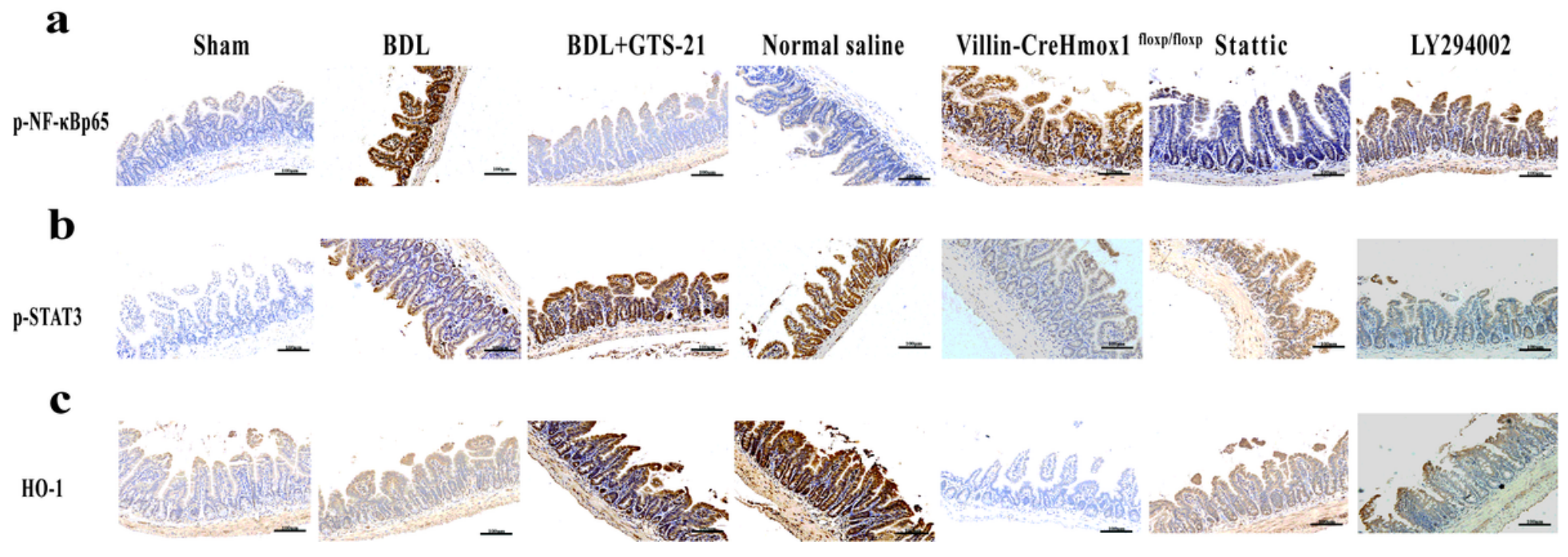

Figure 6

Immunohistochemistry analysis of NF-kBp65, STAT3 activation and HO-1 expression in intestinal tissues of different groups of mice. Data are representative images $(200 x$, scale bar $=10 \mu \mathrm{m})$ from each group of mice ( $n=3$ per group). (a-c) Representative intestinal tissue immunohistochemistry images.

\section{Supplementary Files}

This is a list of supplementary files associated with this preprint. Click to download.

- GraphicalAbstract.png

- SupplementaryMaterials.docx 